\title{
Factors Determing Ignition and Efficient Combustion in Modern Engines Operating on Gaseous Fuels
}

Wladyslaw Mitianiec

Additional information is available at the end of the chapter

http://dx.doi.org/10.5772/48306

\section{Introduction}

Recently in automotive industry the applying of gaseous fuels and particularly compressed natural gas both in SI and CI engines is more often met. However application of CNG in the spark ignition internal combustion engines is more real than never before. There are known many designs of the diesel engines fuelled by the natural gas, where the gas is injected into inlet pipes. Because of the bigger octane number of the natural gas the compression ratio of SI engines can be increased, which takes effect on the increase of the total combustion efficiency. In diesel engines the compression ratio has to be decreased as a result of homogeneity of the mixture flown into the cylinder. Such mixture cannot initiate the self-ignition in traditional diesel engines because of higher value of CNG octane number. Direct injection of the compressed natural gas requires also high energy supplied by the ignition systems. A natural tendency in the development of the piston engines is increasing of the air pressure in the inlet systems by applying of high level of the turbo-charging or mechanical charging. Naturally aspirated SI engine filled by the natural gas has lower value of thermodynamic efficiency than diesel engine. The experiments conducted on SI engine fuelled by CNG with lean homogeneous mixtures show that the better solution is the concept of the stratified charge with CNG injection during the compression stroke. The presented information in the chapter is based on the own research and scientific work partly described in scientific papers. There is a wider discussion of main factors influencing on ignition of natural gas in combustion engines, because of its high temperature of ignition, particularly at high pressure. The chapter presents both theoretical considerations of CNG ignition and experimental work carried out at different air-fuel ratios and initial pressure. 
Gas engines play more and more important role in automotive sector. This is caused by decreasing of crude oil deposits and ecologic requirements given by international institutions concerning to decreasing of toxic components in exhaust gases. Internal combustion engines should reach high power with low specific fuel consumption and indicate very low exhaust gas emission of such chemical components as hydrocarbons, nitrogen oxides, carbon monoxide and particularly for diesel engines soot and particulate matters. Chemical components which are formed during combustion process depend on chemical structure of the used fuel. Particularly for spark ignition engines a high octane number of fuel is needed for using higher compression ratio which increases the thermal engine efficiency and also total efficiency.

\section{Thermal and dynamic properties of gas fuels}

The mixture of the fuel and oxygen ignites only above the defined temperature. This temperature is called as the ignition temperature (self-ignition point). It is depended on many internal and external conditions and therefore it is not constant value. Besides that for many gases and vapours there are distinguished two points: lower and higher ignition points (detonation boundary). These two points determine the boundary values where the ignition of the mixture can follow. The Table 1 presents ignition temperatures of the stoichiometric mixtures of the different fuels with the air.

\begin{tabular}{|l|c|c|c|}
\hline Fuel & Ignition temperature $\left[{ }^{\circ} \mathrm{C}\right]$ & Fuel & Ignition temperature $\left[{ }^{\circ} \mathrm{C}\right]$ \\
\hline Gasoline & $350-520$ & Brown coal & $200-240$ \\
\hline Benzene & $520-600$ & Hard coal atomised & $150-220$ \\
\hline Furnace oil & $\approx 340$ & Coking coal & $\approx 250$ \\
\hline Propane & $\approx 500$ & Soot & $500-600$ \\
\hline Charcoal & $300-425$ & Natural gas & $\approx 650$ \\
\hline Butane $(n)$ & 430 & City gas & $\approx 450$ \\
\hline Furnace oil EL & $230-245$ & Coke & $550-600$ \\
\hline
\end{tabular}

Table 1. Ignition temperatures of the fuels in the air (mean values)

The combustion mixture, which contains the fuel gas and the air, can ignite in strictly defined limits of contents of the fuel in the air. The natural gas consists many hydrocarbons, however it includes mostly above $75 \%$ of methane. For the experimental test one used two types of the natural gas:

1. the certified model gas G20 which contains $100 \%$ of methane compressed in the bottles with pressure 200 bar at lower heat value $47.2-49.2 \mathrm{MJ} / \mathrm{m}^{3}$

2. the certified model gas G25 that contain $86 \%$ of methane and $14 \%$ of N2 at lower heat value $38.2-40.6 \mathrm{MJ} / \mathrm{m}^{3}$.

The natural gas delivered for the industry and households contains the following chemical compounds with adequate mean mass fraction ratios: methane -0.85 , ethane -0.07 , propane - 0.04, n-butane - 0.025, isobutene - 0.005, n-pentane - 0.005, isopentane - 0.005 . 
Because the natural gas contains many hydrocarbons with changeable concentration of the individual species the heat value of the fuel is not constant. It influences also on the ignition process depending on lower ignition temperature of the fuel and energy induced by secondary circuit of the ignition coil. For comparison in Table 2 the ignition limits and temperatures for some technical gases and vapours in the air at pressure 1.013 bars are presented. The data show a much bigger ignition temperature for the natural gas $(640-670$ ${ }^{\circ} \mathrm{C}$ ) than for gasoline vapours $\left(220^{\circ} \mathrm{C}\right)$. For this reason the gasoline-air mixture requires much lower energy for ignition than CNG-air mixture. However, higher pressure during compression process in the engine with higher compression ratio in the charged SI engine causes also higher temperature that can induce the sparking of the mixture by using also a high-energy ignition system. Because of lower contents of the carbon in the fuel, the engines fuelled by the natural gas from ecological point of view emit much lower amount of $\mathrm{CO}_{2}$ and decreases the heat effect on our earth.

Till now there are conducted only some laboratory experiments with the high-energy ignition system for spark ignition engines with direct CNG injection. There are known the ignition systems for low compressed diesel engines fuelled by CNG by the injection to the inlet pipes.

\begin{tabular}{|l|c|c|c|c|}
\hline Type of gas & $\begin{array}{c}\text { Chemical } \\
\text { formula }\end{array}$ & $\begin{array}{c}\text { Normalized } \\
\text { density } \\
\text { (air }=1)\end{array}$ & $\begin{array}{c}\text { Ignition limits in } \\
\text { the air } \\
(\% \text { volumetric) }\end{array}$ & $\begin{array}{c}\text { Ignition } \\
\text { temperature } \\
\left.\text { in the air [ }{ }^{\circ} \mathrm{C}\right]\end{array}$ \\
\hline Gasoline & $\sim \mathrm{C}_{8} \mathrm{H}_{17}$ & 0.61 & $0.6-8$ & 220 \\
\hline Butane (n) & $\mathrm{C}_{4} \mathrm{H}_{10}$ & 2.05 & $1.8-8.5$ & 460 \\
\hline Natural gas H & & 0.67 & $5-14$ & 640 \\
\hline Natural gas L & & 0.67 & $6-14$ & 670 \\
\hline Ethane & $\mathrm{C}_{2} \mathrm{H}_{6}$ & 1,047 & $3-12.5$ & 510 \\
\hline Ethylene & $\mathrm{C}_{2} \mathrm{H}_{4}$ & 1,00 & $2.7-34$ & 425 \\
\hline Gas propane-butane $50 \%$ & & 1.79 & $2-9$ & 470 \\
\hline Methane & $\mathrm{CH}_{4}$ & 0.55 & $5-15$ & 595 \\
\hline Propane & $\mathrm{C}_{3} \mathrm{H}_{8}$ & 1.56 & $2,1-9.5$ & 470 \\
\hline City gas I & & 0.47 & $5-38$ & 550 \\
\hline City gas II & & 0.51 & $6-32$ & 550 \\
\hline Carbon monoxide & $\mathrm{CO}_{2}$ & 0.97 & $12.5-74$ & 605 \\
\hline Hydrogen & $\mathrm{H}_{2}$ & 0.07 & $4-76$ & 585 \\
\hline Diesel oil & & 0.67 & $0.6-6.5$ & 230 \\
\hline
\end{tabular}

Table 2. Ignition limits and ignition temperatures of the most important technical gases and vapours in the air at pressure 1,013 bar

Composition and properties of natural gas used in experimental tests are presented in Table 3. 


\begin{tabular}{|l|l|c|c|c|}
\hline No & \multicolumn{1}{|c|}{ Parameter } & $\begin{array}{c}\text { Nomenclature } \\
\text { or symbol }\end{array}$ & Unit & Value \\
\hline 1 & Combustion heat & $Q_{c}$ & $\begin{array}{c}{\left[\mathrm{MJ} / \mathrm{Nm}^{3}\right]} \\
{[\mathrm{MJ} / \mathrm{kg}]}\end{array}$ & $\begin{array}{l}39,231 \\
51,892\end{array}$ \\
\hline 2 & Calorific value & $W_{d}$ & $\begin{array}{c}{\left[\mathrm{MJ} / \mathrm{Nm}^{3}\right]} \\
{[\mathrm{MJ} / \mathrm{kg}]}\end{array}$ & $\begin{array}{c}35,372 \\
46,788\end{array}$ \\
\hline 3 & Density in normal conditions & $\rho_{g}$ & {$\left[\mathrm{~kg} / \mathrm{Nm}^{3}\right]$} & 0,756 \\
\hline 4 & Relative density & $\Delta$ & - & 0,586 \\
\hline 5 & Coefficient of compressibility & $Z$ & - & 0,9980 \\
\hline 6 & Wobbe number & $W_{B}$ & {$\left[\mathrm{MJ}^{3} / \mathrm{Nm}^{3}\right]$} & 51,248 \\
\hline 7 & Stoichiometric constant & $L_{o}$ & {$\left[\mathrm{Nm}^{3}\right.$ fuel $/ \mathrm{Nm}^{3}$ air $]$} & 9,401 \\
\hline 8 & CO from the combustion & - & {$\left[\mathrm{Nm}^{3} / \mathrm{Nm}^{3}\right]$} & 0,999 \\
\hline
\end{tabular}

Table 3. Properties of the natural gas used in experimental research

\section{Fuelling methods and ignition in gas diesel engines}

Several fuelling methods of the natural gas are applied in modern compression ignition engines, where the most popular are the following cases:

- delivering the gas fuel into the inlet pipes by mixing fuel and air in the special mixer

- small pressure injection of gaseous fuel into the pipe and ignition of the mixture in the cylinder by electric spark

- $\quad$ high pressure direct injection of gaseous fuel particularly in high load engine

There are given the reasons of decreasing of compression ratio in two first methods and the aim of application of gaseous fuels in $\mathrm{CI}$ engines (lowering of $\mathrm{CO}_{2}$, elimination of soot and better formation of fuel mixture). Applying of the two first methods decreases the total engine efficiency in comparison to standard diesel engine as a result of lowering of compression ratio and needs an additional high energetic ignition system to spark disadvantages of application of gas fuel in CI engines. Figure 1 presents an example of variation of heat release of dual fuel naturally aspirated 1-cylinder compression ignition engine Andoria 1HC102 filled by CNG and small amount of diesel oil as ignition dose. This type of engine is very promising because of keeping the same compression ratio and obtaining of higher total efficiency. NG in gaseous forms is pressured into the inlet pipe, next flows by the inlet valve into the cylinder. During compression stroke small dose of diesel oil is delivered by the injector into the combustion chamber as an ignition dose. Because ignition temperature of diesel oil is lower than that of natural gas the ignition start begins from the outer sides of diesel oil streams. In a result of high temperature natural gas the combustion process of the natural gas begins some degrees of CA later. The cylinder contains almost homogenous mixture before the combustion process and for this reason burning of natural gas mixture proceeds longer than that of diesel oil. Figure 1 presents simulation results carried out for this engine in KIVA3V program. 


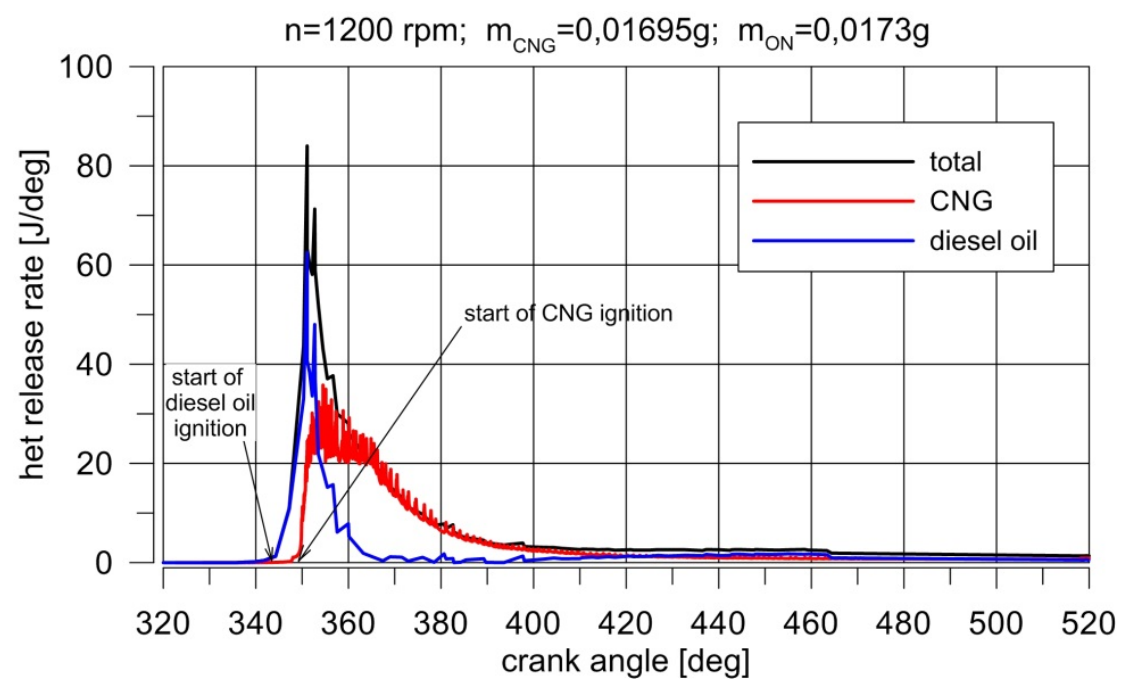

Figure 1. Heat release rate in dual fuel Andoria $1 \mathrm{HC} 102$ diesel engine fuelled by $\mathrm{CNG}$ and ignition dose of diesel oil (index ON- diesel oil, CNG - natural gas)

At higher load of diesel engine with dual fuel a higher mass of natural gas is delivered into the cylinder with the same mass of ignition diesel oil. In order to obtain the same air excess coefficient $\lambda$ as in the standard diesel engine the following formula was used:

$$
\lambda_{e q}=\frac{m_{\text {air }}}{m_{\mathrm{do}}\left(\frac{A}{F}\right)_{\mathrm{do}}+m_{\mathrm{CNG}}\left(\frac{A}{F}\right)_{\mathrm{CNG}}}
$$

where: mair - mass of air in the cylinder,

$m_{d o}$ - mass of diesel oil dose,

$m C N G$ - mass of CNG in the cylinder,

$A / F$ - stoichiometric air-fuel ratio.

At assumed the filling coefficient $\eta_{v}=0,98$ and charging pressure at the moment of closing of the inlet valve $p_{o}=0,1 \mathrm{MPa}$ and charge temperature $T_{o}=350 \mathrm{~K}$, the air mass delivered to the cylinder with piston displacement $V_{s}$ amounts:

$$
m_{\text {air }}=V_{s} \frac{\varepsilon}{\varepsilon-1} \frac{p_{o}}{R T_{o}} \eta_{v}-m_{\mathrm{CNG}}
$$

At the considered dual fuelling the calculated equivalent air excess coefficients after inserting into eq. (2) and next into eq. (1) amounted, respectively: 1) at $\mathrm{n}=1200 \mathrm{rpm}-\lambda_{z}=$ $2,041,2)$ at $\left.\mathrm{n}=1800 \mathrm{rpm}-\lambda_{z}=1,359,3\right)$ at $\mathrm{n}=2200 \mathrm{rpm}-\lambda_{z}=1,073$.

Variation of the mass of natural gas in the dual fuel Andoria 1HC102 diesel engine at rotational speed $2200 \mathrm{rpm}$ is shown in Figure 2. The principal period of combustion process 
of the natural gas lasted about $80 \mathrm{deg}$ CA and its ignition began at TDC. In the real engine the diesel oil injection started at 38 deg CA BTDC.

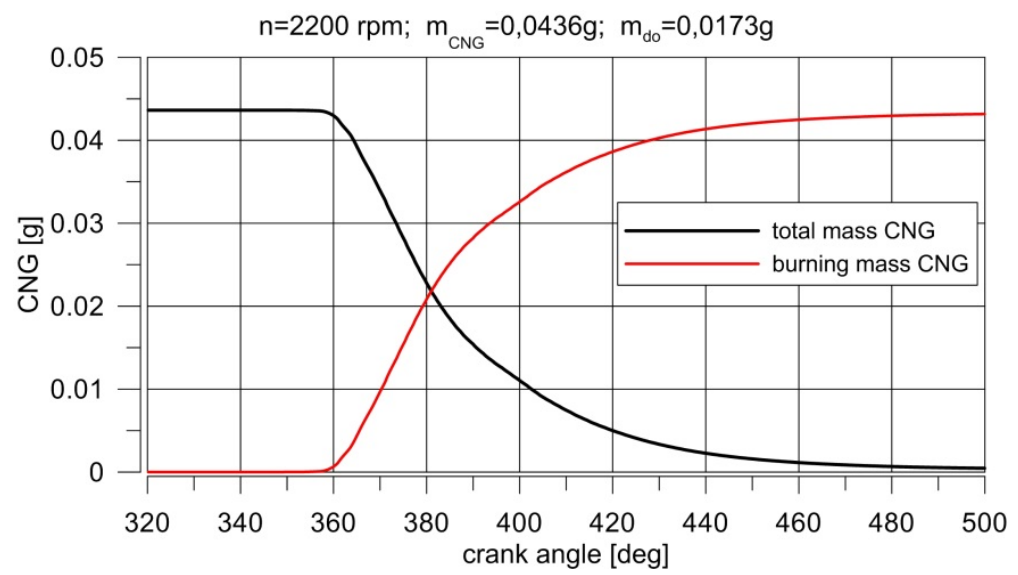

Figure 2. Mass variation of natural gas in Andoria 1HC102 diesel engine fuelled by CNG and ignition dose of diesel oil (index do- diesel oil, CNG - natural gas)

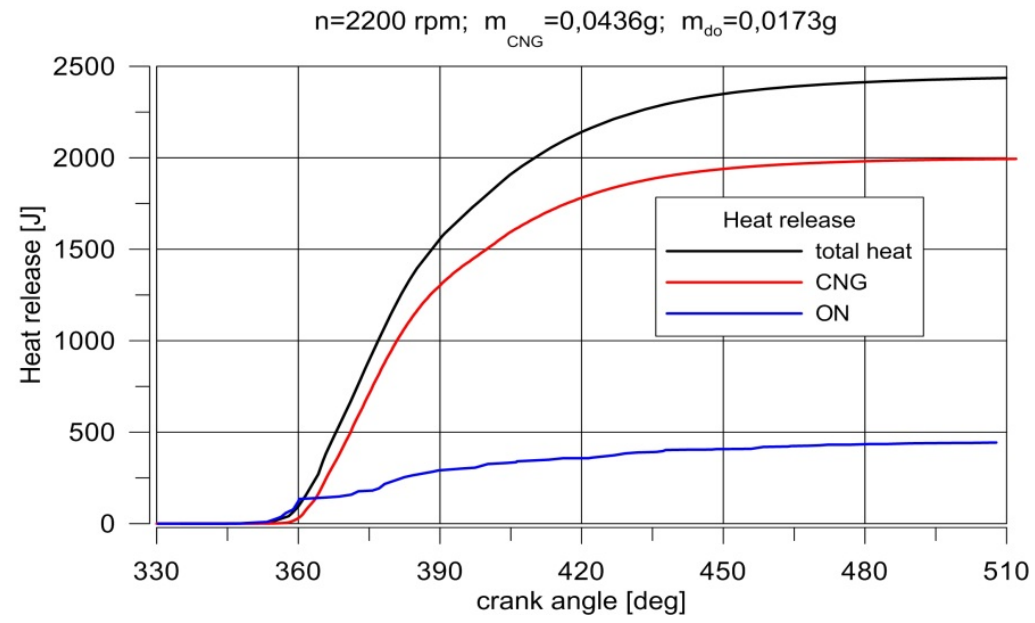

Figure 3. Heat release in dual fuel Andoria 1HC102 diesel engine fuelled by CNG and ignition dose of diesel oil (index do- diesel oil, CNG - natural gas)

Heat release from the both fuels (CNG and diesel oil) is shown in Figure 3 for the same engine at rotational speed $2200 \mathrm{rpm}$. Total heat released during combustion process results mainly on higher burning mass of the natural gas. The ignition process in the gas diesel engines with the ignition dose of diesel oil differs from other systems applied in modified engines fuelled by natural gas delivered into the inlet pipe and next ignited by the spark plug. The initiation of combustion process in CNG diesel engines with spark ignition is almost the same as in the spark ignition engines. 


\section{Ignition conditions of natural gas mixtures}

The flammability of the natural gas is much lower than gasoline vapours or diesel oil in the same temperature. At higher pressure the spark-over is more difficulty than at lower pressure. During the compression stroke the charge near the spark plug can be determined by certain internal energy and turbulence energy. Additional energy given by the spark plug at short time about $2 \mathrm{~ms}$ increases the total energy of the mixture near the spark plug. The flammability of the mixture depends on the concentration of the gaseous fuel and turbulence of the charge near the spark plug. Maximum of pressure and velocity of combustion process in the cylinder for given rotational speed depend on the ignition angle advance before TDC (Figure 4).

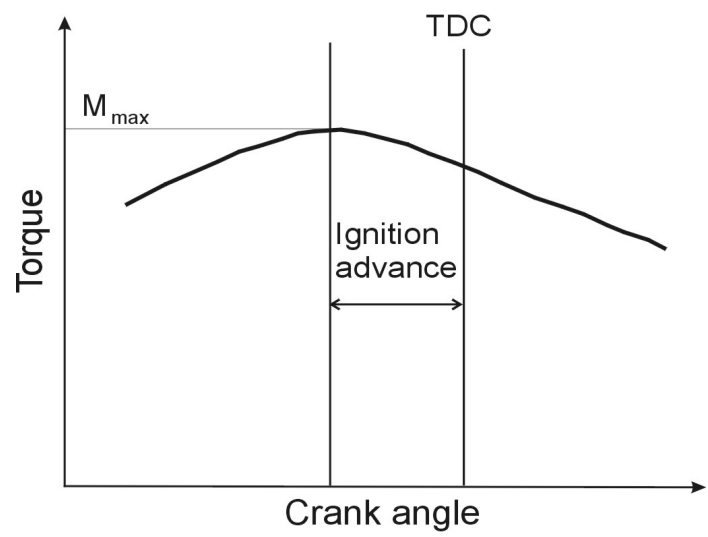

Figure 4. Influence of ignition angle advance on the engine torque

The beginning of the mixture combustion follows after several crank angle rotation. While this period certain chemical reactions follow in the mixture to form the radicals, which can induce the combustion process. The energy in the spark provided a local rise in temperature of several thousand degrees Kelvin, which cause any fuel vapour present to be raised above its auto-ignition temperature. The auto-ignition temperature determines the possibility of the break of the hydrocarbon chains and the charge has sufficient internal energy to oxidize the carbon into $\mathrm{CO}_{2}$ and water in the vapour state. Immediately, after the beginning of combustion (ignition point) the initial flame front close to the spark plug moves in a radial direction into the space of the combustion chamber and heats the unburned layers of air-fuel mixture surrounding it.

For the direct injection of CNG for small loads of the engine in stratified charge mode the burning of the mixture depends on the pressure value at the end of compression stroke and on the relative air-fuel ratio. These dependencies of the CNG burning for different mixture composition and compression ratio are presented in Figure 5 [15]. The burning of CNG mixture can occur in very small range of the compression pressure and lean mixture composition and maximum combustion pressure reaches near 200 bars. For very lean mixtures and higher compression ratios the misfire occurs, on the other hand for rich 
mixtures and high compression ratios the detonation is observed. During the cold start-up the ignition process of the CNG mixture is much easier than with gasoline mixture because of whole fuel is in the gaseous state. Today in the new ignition systems with electronic or capacitor discharge the secondary voltage can reach value $40 \mathrm{kV}$ in some microseconds.

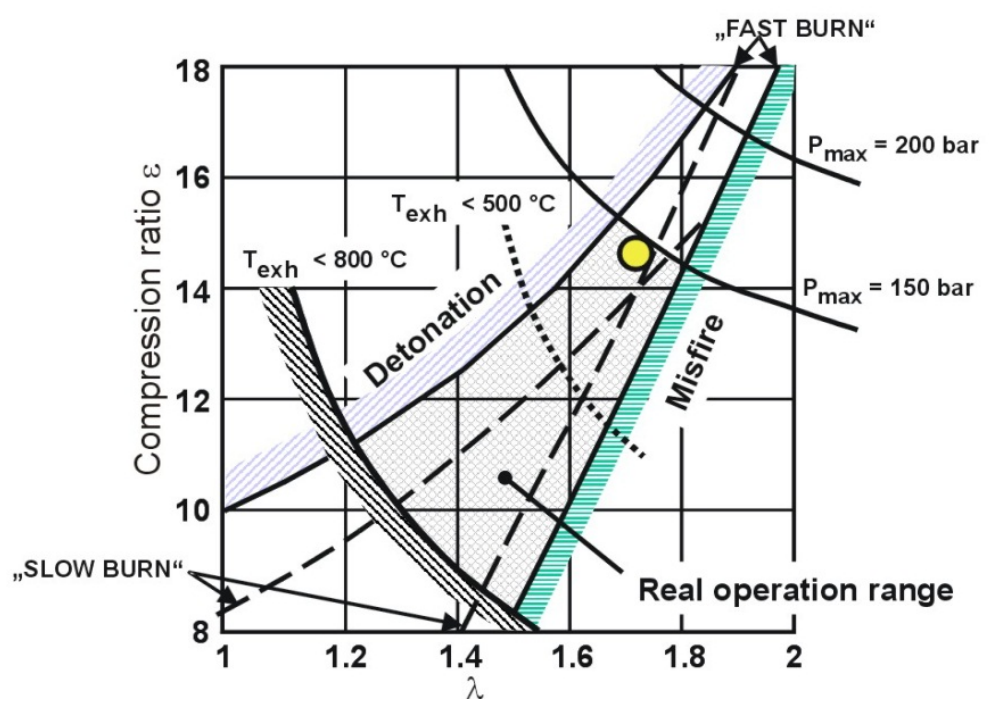

Figure 5. The range of combustion limits for lean CNG mixture [3]

The higher voltage in the secondary circuit of the transformer and the faster spark rise enable that the sparking has occurred even when the spark plug is covered by liquid gasoline. With fuelling of the engine by CNG the sparking process should occur in every condition of the engine loads and speeds. However, at higher compression ratio and higher engine charging the final charge pressure increases dramatically in the moment of ignition and this phenomenon influences on the sparking process.

\section{Electric and thermal parameters of ignition}

On the observation and test done before on the conventional ignition systems, the higher pressure of the charge in the cylinder requires also higher sparking energy or less the gap of the electrodes in the spark plug. The chemical delay of the mixture burning is a function of the pressure, temperature and properties of the mixture and was performed by Spadaccini [12] in the form:

$$
\Delta \tau_{z}=2.43 \cdot 10^{-9} p^{-2} \cdot \exp [41560 /(R \cdot T)]
$$

where: $p$ - pressure [bar], $T$ - temperature $[\mathrm{K}]$ and $R$ - gas constant $\left[\left(\mathrm{bar} \mathrm{cm}^{3}\right) /(\mathrm{mol} \mathrm{K})\right]$.

The simplest definition of this delay was given by Arrhenius on the basis of a semiempirical dependence: 


$$
\Delta \tau_{z}=0.44 \cdot 10^{-3} \cdot p^{-1.19} \exp \left[\frac{4650}{T}\right]
$$

where $p$ is the charge pressure at the end of the compression process [ $\left.\mathrm{daN} / \mathrm{cm}^{2}\right]$.

Experimental and theoretical studies divide the spark ignition into three phases: breakdown, arc and glow discharge. They all have particular electrical properties. The plasma of temperature above $6000 \mathrm{~K}$ and diameter equal the diameter of the electrodes causes a shock pressure wave during several microseconds. At an early stage a cylindrical channel of ionization about $40 \mu \mathrm{m}$ in diameter develops, together with a pressure jump and a rapid temperature rise. Maly and Vogel [10] showed that an increase in breakdown energy does not manifest itself a higher kernel temperatures, instead the channel diameter causing a larger activated-gas volume. Since the ratio between the initial temperature of the mixture and the temperature of the spark channel is much smaller than unity, the diameter $d$ of the cylindrical channel is given approximately by the following expression:

$$
d=2\left[(\gamma-1) \frac{E_{b d}}{\gamma \cdot \pi \cdot h \cdot p}\right]^{1 / 2}
$$

where $\gamma$ is ratio of the specific heats, $h$ is the spark plug gap and $p$ pressure. Ebd represents the breakdown energy to produce the plasma kernel. Ballal and Lefebvre [6] considered the following expression for the breakdown voltage $U_{b d}$ and total spark energy $E_{t}$ :

$$
U_{b d}=\frac{2,8 \cdot 10^{5} \cdot p \cdot h}{5,5-\ln (p \cdot d)} \quad E_{t}=\int_{0}^{t_{i}} V \cdot I \cdot d t
$$

One assumed, that the charge is isentropic conductive and the field attains a quasi-steady state (no time influence). Knowing the potential of the electromagnetic field $\Phi$ and electrical conductivity $\sigma$ the following equation can be used [12]:

$$
\operatorname{div}(-\sigma \cdot \operatorname{grad} \Phi)=0
$$

After a forming of the plasma between the electrodes the heat source $\dot{q}_{e}$ in the mixture can be calculated directly from the electrical current in the secondary coil circuit I, which changes during with time:

$$
\dot{q}_{e}=\sigma \frac{I^{2}}{\left(\int_{0}^{R} 2 \pi r \sigma(r, z) d r\right)^{2}}
$$

where $r$ and $z$ are the coordinates of the ionization volume.

At leaner homogenous mixture the discharging of the energy by spark plug leads sometimes to the misfire and increasing of the hydrocarbons emission. At stratified charge for the same 
total air-fuel ratio the sparking of the mixture can be improved by turning the injected fuel directly near spark plug at strictly defined crank angle rotation depending on the engine speed. The energy involved from the spark plug is delivered to the small volume near spark plug. The total energy, which is induced by the spark plug is a function of the voltage and current values in the secondary circuit of the ignition coil and time of the discharge. On the other hand, values of voltage $U$ and current $I$ change in the discharge time and total energy induced by the coil can be expressed as a integral of voltage $U$, current $I$ and time $t$ :

$$
E_{i g n}=\int_{0}^{\tau} U \cdot I \cdot d t
$$

where $\tau$ is the time of current discharge by the secondary circuit of the ignition coil. Integration of the measurement values of voltage and current in the secondary circuit of the coil gives the total electric energy to the mixture charge near spark plug. The total internal energy of the mixture near the spark plug increases in the period $t=0 . . \tau$ and according to the energy balance in the small volume the temperature of the charge in this region continuously increases.

The modern conventional ignition system can give the burning energy $e_{b u r n}=60 \mathrm{~mJ}$ at the secondary voltage $30 \mathrm{kV}$ and burning current $i_{\text {burn }}=70 \mathrm{~mA}$ during $1.8 \mathrm{~ms}$. In practice a required value of the secondary voltage of the ignition system is calculated from the following formula:

$$
U_{2}=4700 \cdot(a \cdot \varepsilon)^{0.718}
$$

where: $U_{2}$ - secondary voltage $[\mathrm{V}]$,

$a$ - gap between electrodes of the spark plug, $\varepsilon$ - compression ratio.

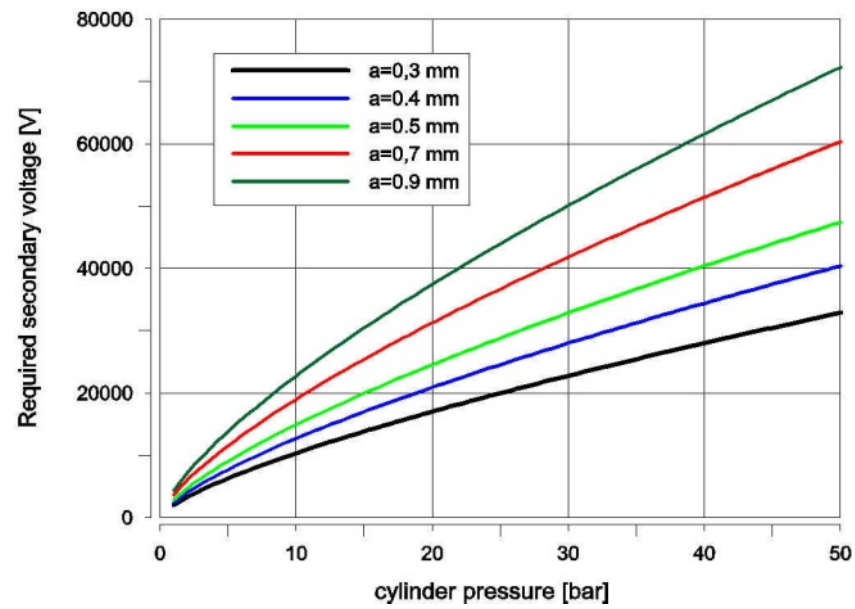

Figure 6. The secondary voltage as a function of compression pressure and electrode's gap 
For lower gaps and compression ratios the secondary voltage can be decreased. The required secondary voltage as a function of compression pressure is presented in Figure 6 for different gaps of spark plug electrodes from 0.3 to $0.9 \mathrm{~mm}$.

If one assumes that the electrical energy $E$ is delivered during period $\tau$ to a certain small volume $V$ near spark plug with the temperature of the charge $T_{1}$ and pressure $p_{1}$ and concentration of CNG fuel adequate to the air excess coefficient $\lambda$, it is possible to calculate the change of the charge temperature in this space. On the basis of the law of gas state and balance of energy the specific internal energy $u$ of the charge in the next step of calculation is defined.

$$
u_{i}=u_{i-1}+d E
$$

where $i$ is the step of calculations and $d E$ is the energy delivered from the spark plug in step time $d \tau$. The internal energy is function of the charge mass $m$ and temperature $T$, where mass $m$ in volume $V$ is calculated from the following dependency:

$$
m=\frac{p_{1} \cdot V}{R \cdot T_{1}}
$$

and gas constant $R$ is calculated on the mass concentration $g$ of the $\mathrm{n}$ species in the mixture. Mass of the charge consists of the fuel mass $m_{f}$ and air mass $m_{a}$, which means:

$$
m=m_{a}+m_{f}
$$

For the mixture that contains only air and fuel (in our case $\mathrm{CNG}$ ), the equivalent gas constant is calculated as follows:

$$
R=\sum_{1}^{n} g_{i} \cdot R_{i}=g_{a} \cdot R_{a}+g_{f} \cdot R_{f}
$$

In simple calculations the local relative air-fuel ratio $\lambda$ is obtained from the local concentration of air and fuel:

$$
\lambda=\frac{m_{a}}{K \cdot m_{f}}
$$

where $K$ is stoichiometric coefficient for a given fuel. For the CNG applied during the experiments $\mathrm{K}=16.04$ [ $\mathrm{kg}$ air $/ \mathrm{kg} \mathrm{CNG}$ ]. At assumption of the relative air-fuel ratio $\lambda$ the masses of fuel $m_{f}$ and air $m_{a}$ can be obtained from the following formulas:

$$
m_{f}=\frac{m}{\lambda K+1} \quad m_{a}=m \frac{\lambda K}{\lambda K+1}
$$

After substitution of the fuel and air masses to the equation (10) the equivalence gas constant $R$ is defined only if the $\lambda$ is known. 


$$
R=\frac{1}{\lambda K+1}\left(\lambda \cdot K \cdot R_{a}+R_{f}\right)
$$

For whole volume $V$ the internal energy at the beginning of the ignition is defined as:

$$
U_{1}=m \cdot c_{v} \cdot T_{1}=\frac{p_{1} \cdot V}{R \cdot T_{1}} \cdot c_{v} \cdot T_{1}=\frac{p_{1} \cdot V}{R} \cdot c_{v}
$$

The charge pressure during compression process increases as function of the crank angle rotation from $p_{1}$ to $p$. When one knows the engine's stroke $S$ and diameter $D$ of the cylinder and compression ratio $\varepsilon$ it is possible to determine the change of pressure from start point to another point. If the heat transfer will be neglected the pressure change in the cylinder can be obtained from a simple formula as a function of time $t$ and engine speed $n$ (rev/min):

$$
\frac{d p}{d t}=-\frac{30}{\pi} \frac{k-1}{n \cdot V_{c}}\left(\frac{k}{k-1} \frac{d V_{c}}{d t}\right)
$$

where $V_{c}$ is volume of the cylinder at crank angle $\varphi$ and $k$ is specific heat ratio $\left(c_{p} / c_{v}\right)$.

For simplicity of calculations it was assumed that during compression stroke the specific heat ratio for small period is constant $(k \approx 1.36)$ and cylinder volume changes with kinematics of crank mechanism. Delivery of electrical energy to the local volume results on the increase of local internal energy and changing of temperature $T$, which can be determined from the following energy equation:

$$
m \cdot c_{v} \cdot T_{i}=m \cdot c_{v} \cdot T_{i-1}+d e \text { or } m \cdot c_{v} \cdot \frac{d T}{d t}=\frac{d e}{d t}
$$

The electrical energy can be performed in a different way: with constant value during time $\tau$ (rectangular form or according to the reality in a triangular form as shown in Figure 7.

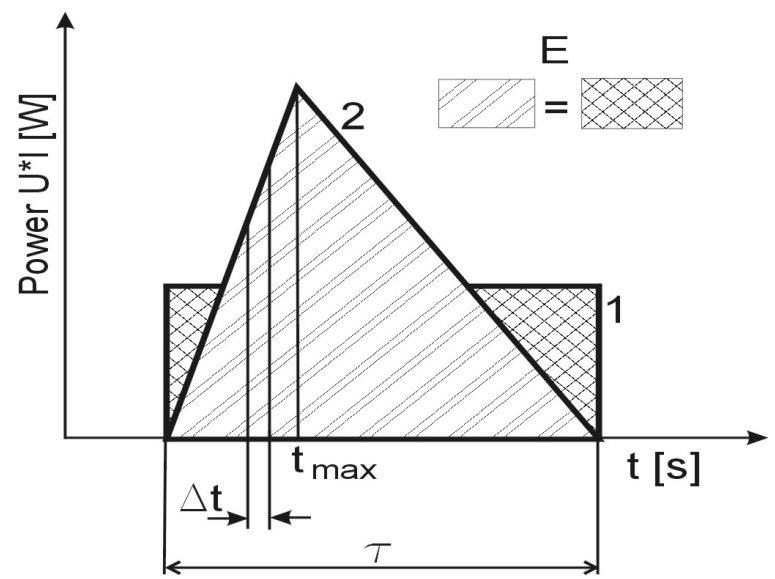

Figure 7. Variation of electrical power from spark plug 
If the total electrical energy amounts $E$ and duration of sparking lasts $\tau(1.8 \mathrm{~ms})$ then for the first case the local power is $E / \tau$ for whole period $\tau$ of the sparking. For the second case electrical power from the spark plug changes and for the first period can be expressed as:

$$
N_{I}=\frac{t}{t_{\max }} \frac{2 E}{\tau}
$$

For the second period the electrical power can be determined as follows:

$$
N_{I I}=\frac{1-t / \tau}{1-t_{\max } / \tau} \cdot \frac{2 \cdot E}{\tau}
$$

The temperature of the charge near the spark plug during the period $\tau$ is computed as follows:

$$
d T=\frac{1}{m \cdot c_{v}} N(t) \cdot d t
$$

For the first case (rectangular form) of variation of electrical power the change of the charge temperature is computed from the following dependency:

$$
d T=\frac{1}{m \cdot c_{v}} \cdot \frac{E}{\tau} \cdot d t
$$

For the second case (triangular form of power) the temperature of the local charge is calculated as follows:

a. $1^{\text {st }}$ period

$$
d T=\frac{1}{m \cdot c_{v}} \cdot \frac{t}{t_{\max }} \cdot \frac{2 E}{\tau} \cdot d t
$$

b. $\quad 2^{\text {nd }}$ period

$$
d T=\frac{1}{m \cdot c_{v}} \cdot \frac{1-\frac{t}{\tau}}{1-\frac{t_{\max }}{\tau}} \cdot \frac{2 \cdot E}{\tau} \cdot d t
$$

At assuming of specific volumetric heat $c_{v}$ as constant in a small period $\tau$ the temperature of the local charge is simply obtained by integration of given above equations as function of time $t(t=0 . . \tau)$

$$
\text { 1. } \quad T=T_{1}+\frac{E}{m \cdot c_{v}} \frac{t}{\tau}
$$




$$
\begin{aligned}
& \text { 2a. } \quad T=T_{1}+\frac{E}{m \cdot c_{v}} \cdot \frac{\tau}{t_{\max }} \cdot\left(\frac{t}{\tau}\right)^{2} \\
& \text { 2b. } \quad T=C+\frac{1}{m \cdot c_{v}} \cdot \frac{2 \cdot E}{1-\frac{t_{\max }}{\tau}} \cdot \frac{t}{\tau}\left(1-\frac{t}{2 \tau}\right)
\end{aligned}
$$

The constant $C$ is calculated for the initial conditions for $t / \tau=t_{\max } / \tau$ with the end temperature for $1^{\text {st }}$ period as an initial temperature for $2^{\text {nd }}$ period. The three cases are performed in a nondimensional time $t / \tau$. Because compression stroke in 4-stroke engine begins usually $\varphi_{a}=45^{\circ}$ CA ABDC and thus the cylinder volume [3] can be calculated at $\varphi_{i}$ crank angle as follows:

$$
V_{a}=\frac{V_{s}}{\varepsilon-1}+\frac{V_{s}}{2}\left(1+\frac{\delta}{4}-\cos \left(180-\varphi_{i}\right)-\frac{\delta}{4} \cos 2\left(180-\varphi_{i}\right)\right)
$$

The simple calculations of the increment of the local temperature in the region of the spark plug were done at certain assumptions given below: swept volume of the cylinder $-450 \mathrm{~cm}^{3}$, compression ratio -12, crank constant $\delta-0.25$, diameter of sparking region - $1 \mathrm{~mm}$, height of sparking region $-1 \mathrm{~mm}$, closing of inlet valve $-45^{\circ} \mathrm{CA} \mathrm{ABDC}$, start angle of ignition - $20^{\circ}$ CA BTDC.

For calculation the air-gas mixture was treated as an ideal gas (methane $\mathrm{CH}_{4}$ and air at $\lambda=1.4$ ). Two ignition systems were considered with ignition energy 40 and $60 \mathrm{~mJ}$ at assumption of:

1. constant sparking power (rectangular form) in period $\tau=2 \mathrm{~ms}$

2. variable sparking power (triangular form) in period $\tau=2 \mathrm{~ms}$.

The results of calculations are performed in Figure 8 for those two ignition systems, respectively. It was assumed that compression process begins after closing of the inlet valve with constant coefficient of compression politrope $k=1.36$.

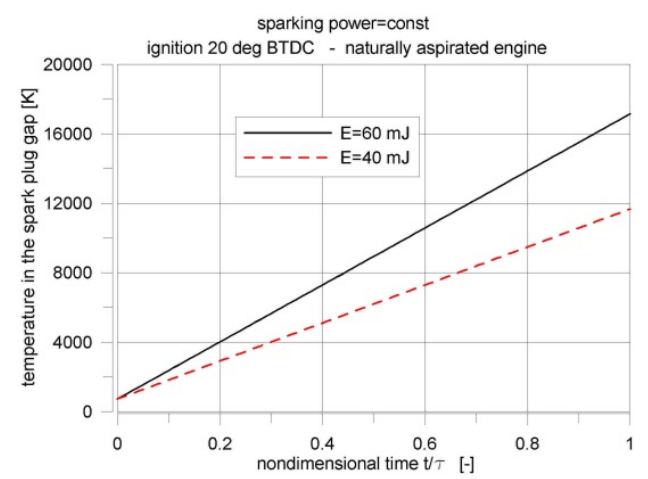

(a)

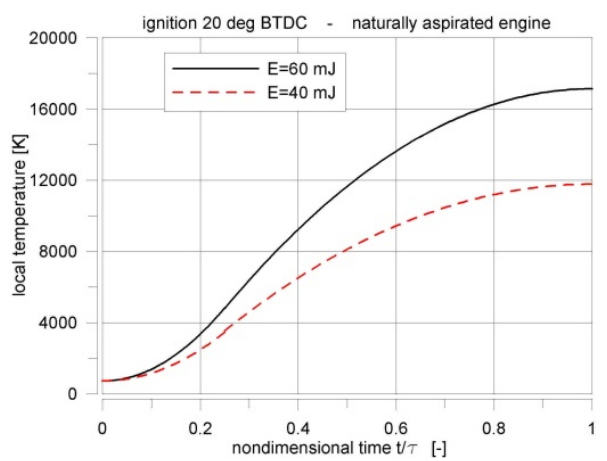

(b)

Figure 8. Increment of the local temperature in the region of the spark plug for two ignition systems: a) with constant sparking power, b) with variable sparking power (triangular form) 
In the moment of the sparking start the pressure in the cylinder amounts $1.577 \mathrm{MPa}$ at temperature $726 \mathrm{~K}$. Theoretical consumption of the air for combustion of $1 \mathrm{Nm}^{3}$ of the natural gas amounts $9.401 \mathrm{Nm}^{3}$. For given concentration of the air and fuel (CNG) in the mixture the gas constant is $\mathrm{R}=296.9 \mathrm{~J} /(\mathrm{kg} \mathrm{K})$ and calculated mass of charge in the region amounts $0.465 \mathrm{e}-8 \mathrm{~kg}$. As shown in both figures the final temperature in the region is the same for two considered variations of power. If the volume of the sparking region decreases the local temperature will increase, however ignition of the mixture depends on concentration of the fuel in the air. The final temperature does not depend on the shape of the ignition power during sparking but only on the total energy released during the sparking. In the gap of the electrodes at ignition energy $60 \mathrm{~mJ}$ a mean temperature amounts almost $17000 \mathrm{~K}$ after $2 \mathrm{~ms}$ and at $40 \mathrm{~mJ}$ amounts $12000 \mathrm{~K}$. This is enough to ignite the mixture.

\section{Determination of thermal efficiency}

Only a small part of the delivered energy from the second circuit is consumed by gaseous medium, which is observed by increase of the temperature $\Delta T$ and thus also internal energy $E$. The thermal efficiency of the ignition system is defined as ratio of the increase of internal energy and energy in the secondary circuit of the ignition coil:

$$
\eta_{t h}=\frac{\Delta E_{i}}{E_{2}}=\frac{\Delta E_{i} \cdot E_{1}}{E_{2} \cdot E_{1}}=\eta_{o} \cdot \eta_{e}
$$

where $E_{1}$ is the energy in the primary circuit and $\eta_{0}$ is the total efficiency and $\eta_{e}$ is the electric efficiency of the ignition system. The increase of the internal energy in volume $V$ with initial pressure $p_{1}$ can be determined as follows:

$$
\Delta E_{i}=m \cdot c_{v} \cdot \Delta T
$$

Assuming a constant mass and individual gas constant $R$, the temperature after ignition can be defined from the gas state equation. At small change of the gas temperature from $T_{1}$ to $T_{2}$ the volumetric specific heat $c_{v}$ has the same value. In such way it is possible to determine the increase of the internal energy:

$$
\Delta E_{i}=\frac{p_{1} \cdot V}{R \cdot T_{1}} \cdot c_{v} \cdot\left(T_{2}-T_{1}\right)=\frac{p_{1} \cdot V}{R \cdot T_{1}} \cdot c_{v} \cdot\left(T_{1} \cdot \frac{p_{2}}{p_{1}}-T_{1}\right)
$$

After simplification this equation takes the form:

$$
\Delta E_{i}=\frac{V}{R} \cdot c_{v} \cdot\left(p_{2}-p_{1}\right)=\frac{V}{R} \cdot c_{v} \cdot \Delta p
$$

The increase of the internal energy depends on the sparking volume, gas properties and a pressure increment in this volume. Because of constant volume and known $R$ and $c_{v}$ the unknown value is only the increment of the pressure $\Delta p$. The direct method of measurement 
is using the pressure piezoelectric transducer with big sensitivity and with high limit of static pressure. For that case we have used the sensor PCB Piezotronic 106B51 (USA) with the following parameters:

- $\quad$ Measurement range (for $\pm 5 \mathrm{~V}$ output)

- Maximum pressure (step)

- Maximum pressure (static)

- Sensitivity $( \pm 15 \%)$
$35 \mathrm{kPa}$

$690 \mathrm{kPa}$

$3448 \mathrm{kPa}$

$145 \mathrm{mV} / \mathrm{kPa}$

For that sensor the amplifier Energocontrol VibAmp PA-3000 was used. The filling of the chamber with fixing of the spark plug and transducer is presented in Figure 9. The additional (medium) chamber with capacity $200 \mathrm{~cm}^{3}$ is filled under given pressure (shown on the manometer) from the pressure bottle. The caloric chamber is filled from this medium chamber by the special needle valves. After sparking the chamber was emptied by opening the other needle valve. The needle valves were used in order to decrease the dead volume in the pipes connecting the chamber. The total volume was measured by filling the chamber by water and amounts $4,1 \mathrm{~cm}^{3}$.

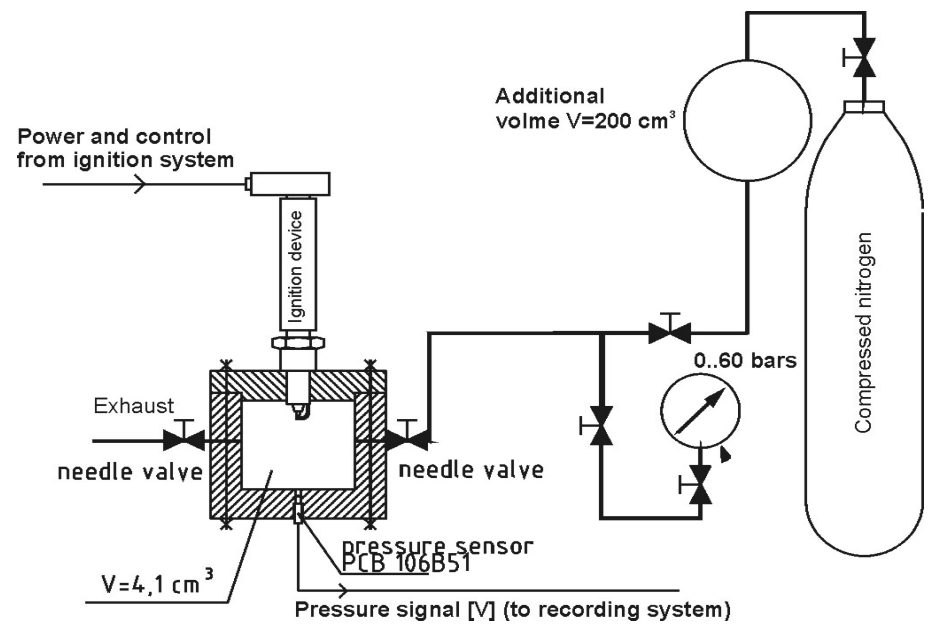

Figure 9. Scheme of the direct measurement pressure in the caloric chamber

The target of the tests was to determine the amount of thermal energy delivered do the charge in the chamber after the sparking; it means the measurements of the pressure increment in function of initial pressure. For one point of each characteristic we carried out 10 measurements. For the tests two types of electrodes were used: the normal with $2.8 \mathrm{~mm}$ width and the "thin" with $25 \%$ cross-section of the first type. The measurements were carried out in nitrogen and air at initial pressure in the chamber corresponded to ambient conditions (over pressure 0 bar) and at 25 bars. For the "thin" electrodes there is observed a bigger increment of the pressure than while using the spark plug with normal electrodes both at low as at high initial pressure, despite the delivered energy from the secondary circuit of the coil is almost the same. Increment of pressure inside the chamber caused by 
energy delivered from spark plug is shown in Figure 10 for initial pressure 1 bar and 25 bars and by application of the spark plug with "thin" and "thick" electrodes.

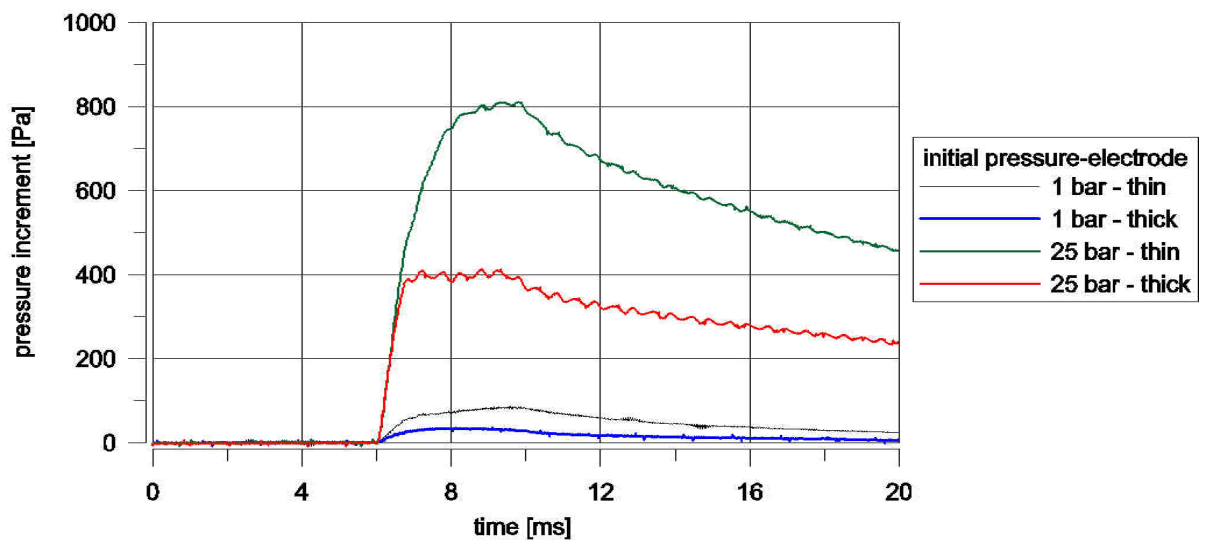

Figure 10. Pressure increment in caloric chamber filled by nitrogen at initial pressure 1 and 25 bars by application of spark plug with "thin" and "thick" electrodes

The duration of the sparking lasted about $4 \mathrm{~ms}$ and after this time the decrement of the pressure is observed which is caused by heat exchange with walls of the caloric chamber. In every case at the end of ignition process the sudden increase of secondary voltage takes place. The current in the secondary circuit of the ignition coil increases rapidly to about 80 $\mathrm{mA}$ after signal of the ignition and then decreases slowly during $4 \mathrm{~ms}$ to zero as one shows in Figure 11 for all considered cases.

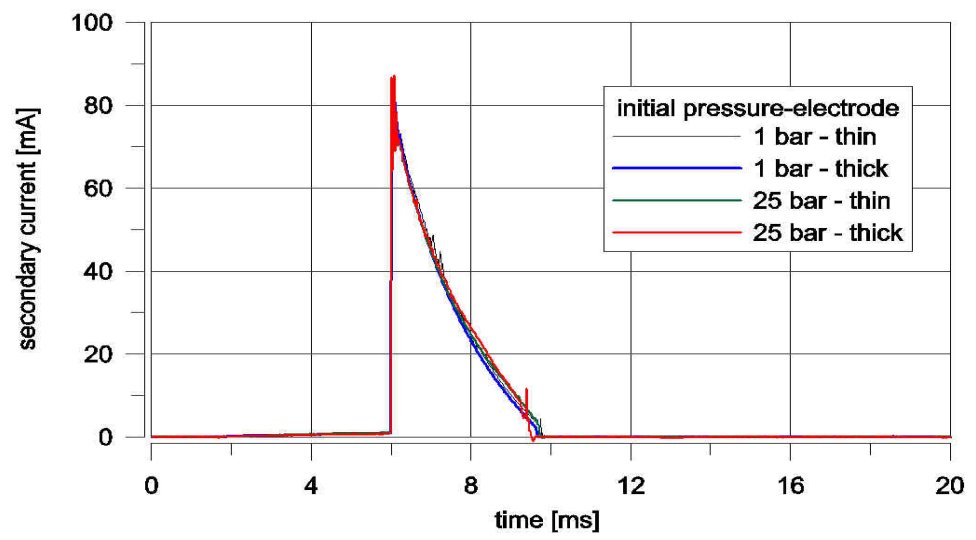

Figure 11. Secondary current in the coil during the ignition in the caloric chamber filled by nitrogen at initial pressure 1 and 25 bar by application of spark plug with "thin" and "thick" electrodes

Variation of voltage in the secondary circuit is shown in Figure 12. For the considered ignition coil one reaches maximum voltage $3000 \mathrm{~V}$ in the case of higher initial pressure 30 bar. In every case at the end of ignition process the sudden increase of secondary voltage 
takes place. Thermal energy delivered to the spark plug (in the secondary circuit) was determined by integration of instant electric power (multiplication of current and voltage) with small time step. For the case with "thin" electrodes and at 1 bar the thermal energy amounts only $0,89 \mathrm{~mJ}$ and thus the thermal efficiency is about $\eta_{\text {th }}=1,29 \%$ (Figure 13). For normal electrodes at the same pressure the thermal energy is very lower $0,36 \mathrm{~mJ}$ which causes a small thermal efficiency $\eta_{t h}=0,51 \%$.

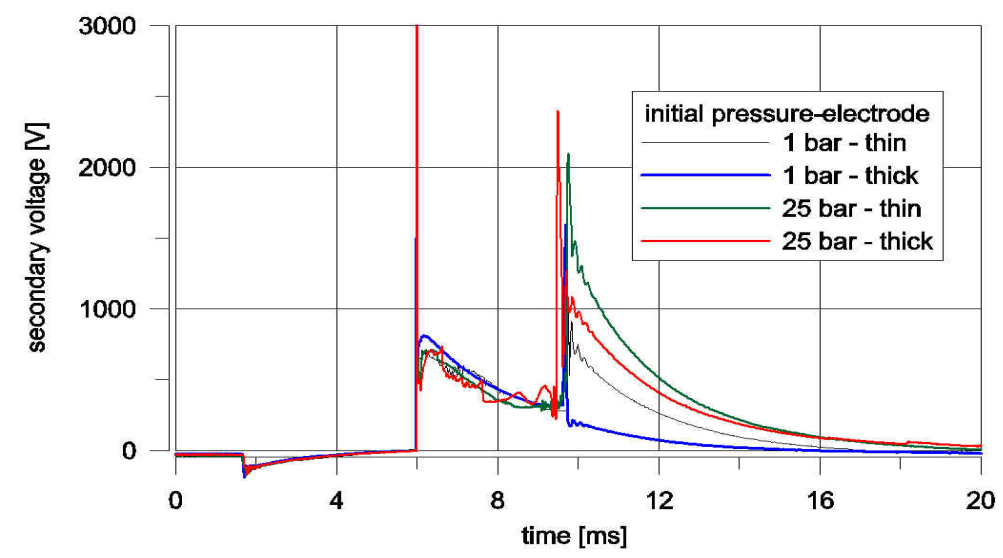

Figure 12. Secondary voltage in the coil during the ignition in the caloric chamber filled by nitrogen at initial pressure 1 and 25 bars by application of spark plug with "thin" and "thick" electrodes
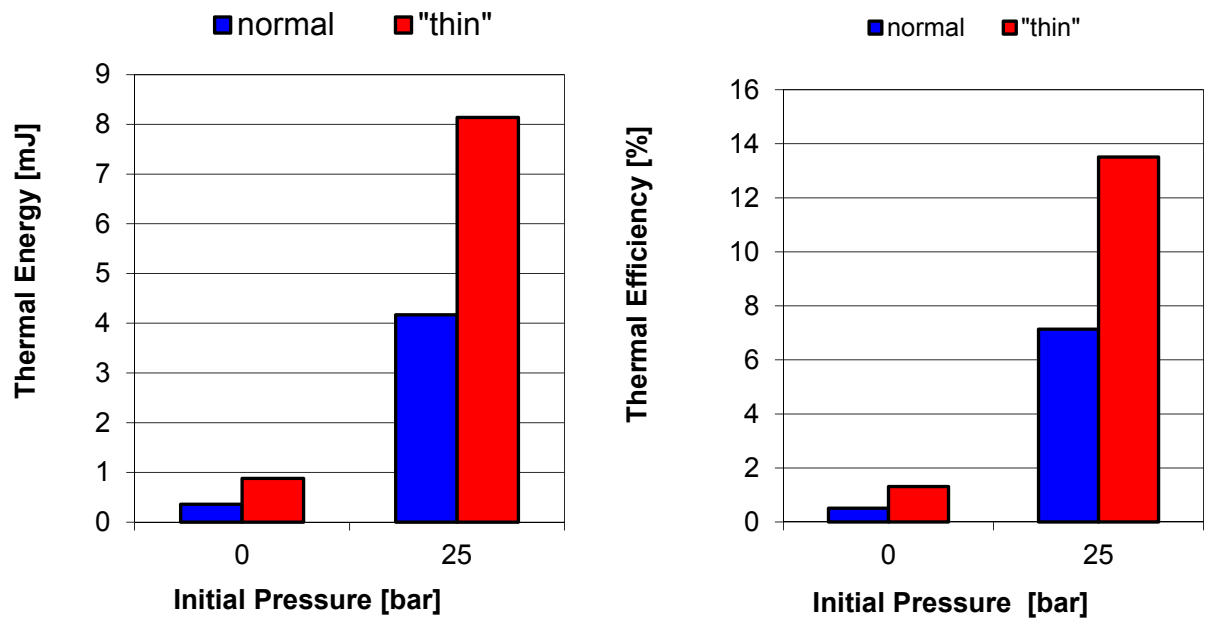

Figure 13. The comparison of the thermal energy and thermal efficiency for spark plug with normal and "thin" electrodes at two initial positive gauge pressures

The thermal energy and thermal efficiency increases with the increase of the initial pressure. For the case with "thin" electrodes of the spark plug the thermal efficiency amounts $13.49 \%$, 
on the other hand for normal electrodes only $6.93 \%$. The tests were done for five ignition systems from BERU at different initial pressure $(0-25$ bars $)$ and linear approximation variations of the thermal efficiencies are shown in Figure 14. With increasing of the pressure in the caloric chamber much more energy is delivered from the electric arc to the gas. The measurements of the pressure increase during spark ignition were carried out also for the air and the same pressures. Figure 16 presents the increase of secondary voltage in the ignition coil with increasing of initial pressure in the caloric chamber. For nitrogen and leaner mixtures a higher secondary voltage in the coil was measured.

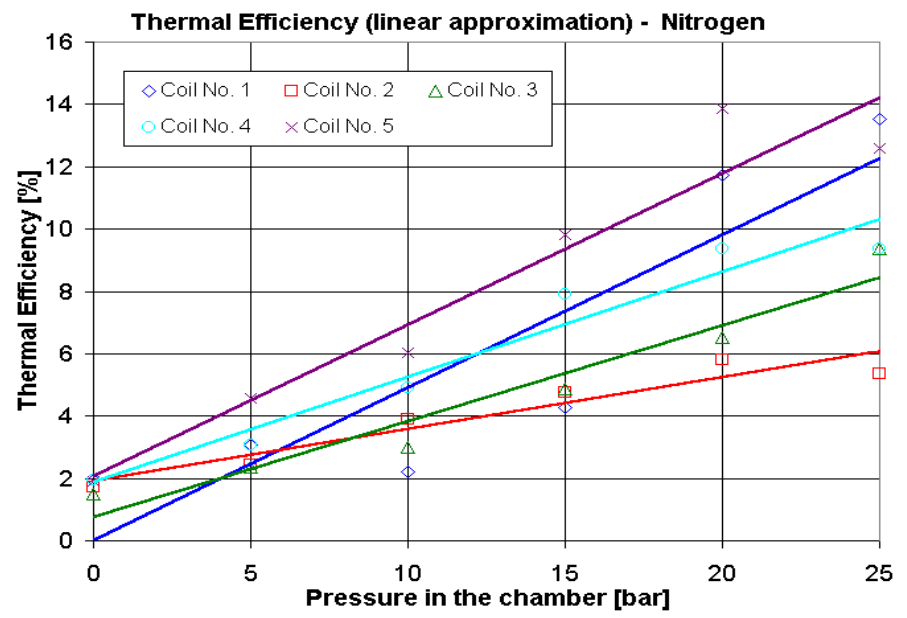

Figure 14. Thermal efficiency of five tested ignition systems

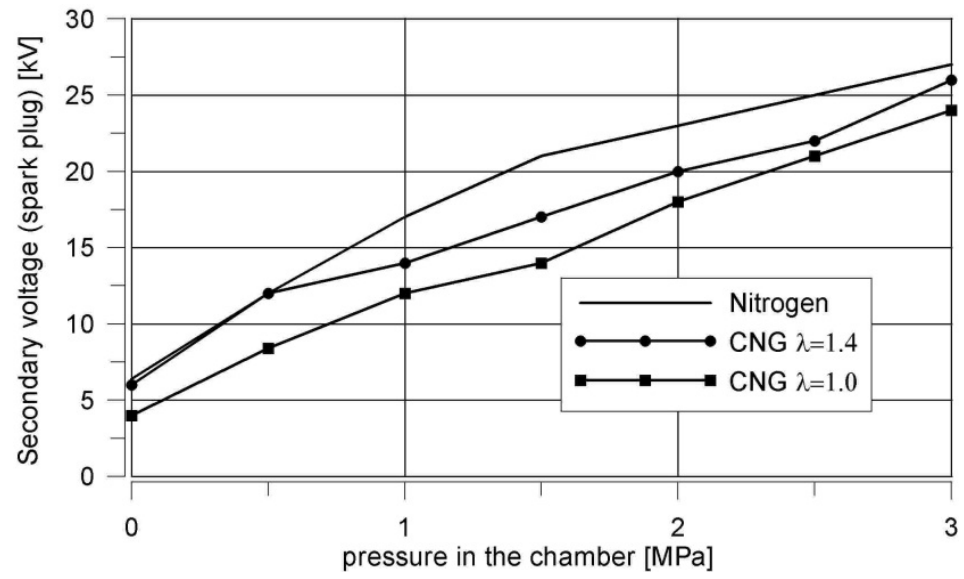

Figure 15. Influence of initial pressure on secondary voltage in ignition coil measured in caloric chamber filled by nitrogen and natural gas 


\section{Determination of energy losses during ignition}

The model of ignition process takes into account only a small part of the spark plug and is shown in Figure 16.

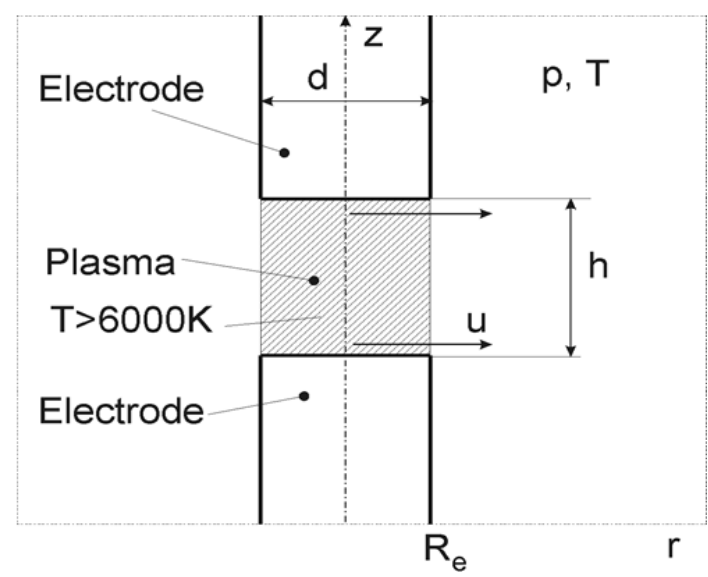

Figure 16. Model of spark ignition

During the sparking the plasma is formed between two electrodes and it is assumed to be smaller than the thickness of these electrodes. After short time a pressure shock takes place and the charge is moving on outer side with high velocity [1] [13]. The energy delivered directly to the charge is very low and therefore the energy losses should be assessed. As the experimental test showed, only a small part of delivered energy is consumed to increase the internal energy of the charge (maximum 10\%). The energy losses during the ignition process can be divided into several kinds: radiation, breakdown, heat exchange with electrodes, kinetic energy which causes the turbulence, electromagnetic waves, flash and others.

\subsection{Radiation energy of ignition}

The part of the spark energy is consumed by radiation of the plasma kernel. The temperature $T$ of plasma between two electrodes is above $6000 \mathrm{~K}$. At assumption of the Boltzman radiation constant $k=5.67 \mathrm{~W} /\left(\mathrm{m}^{2} \mathrm{~K}^{4}\right)$ and the coefficient of emissivity $\varepsilon$ of a grey substance [9] for the ignition arc, the specific heat radiation $e$ can be obtained from the formula:

$$
e=\varepsilon \cdot k \cdot\left(\frac{T}{100}\right)^{4}
$$

The emissivity of the light grey substance was defined by Ramos and Flyn [4] and they amounted it in the range of $0.2-0.4$. For that case it was assumed that $\varepsilon=0.3$. The total radiation energy is a function of the ignition core surface $A_{i}$ and sparking time $t_{i}$ : 


$$
d E_{r}=A_{i} \cdot \mathrm{d} e \cdot \mathrm{d} t=A_{i} \cdot \varepsilon \cdot k \cdot\left(\frac{T}{100}\right)^{4} \cdot \mathrm{d} t
$$

At assumption that the temperature $T$ of the arc increases proportionally with time from $6000 \mathrm{~K}$ to $300 \mathrm{~K}$ the total radiation energy can be calculated as follows:

$$
E_{r}=A_{i} \cdot \varepsilon \cdot k \cdot \int_{0}^{t_{i}}\left(\frac{T}{100}\right)^{4} \mathrm{~d} t=A_{i} \cdot \varepsilon \cdot k \cdot\left(\int_{0}^{t_{i}}\left(\frac{\left(T_{\max }-T_{2}\right) \cdot t}{t_{i} \cdot 100}\right)^{4} \cdot d t+\int_{0}^{t_{i}}\left(\frac{\left(T_{\max }-T_{2}\right) \cdot t}{t_{i} \cdot 100}\right)^{4} \cdot d t\right)
$$

Assuming the radial shape of the core equal the radius $d / 2$ of the electrodes and its height $h$ equal the gap of electrodes and also that maximum temperature of the arc amounts $6000 \mathrm{~K}$ after $t_{1}=20 \mu \mathrm{s}$ and then decreases to $800 \mathrm{~K}$ after $t_{2}=2 \mathrm{~ms}$, we can calculate the part of the coil energy as a loss of the radiation energy. Because $20 \mu$ s is comparably small with $2 \mathrm{~ms}$ then the equation (14) can be rewritten as follows:

$$
E_{r}=\frac{A_{i} \cdot \varepsilon \cdot k \cdot\left(T_{\max }-T_{2}\right)}{10^{8}} \cdot \frac{t_{i}}{5}
$$

where $A_{i}$ - the surface of the plasma core amounts $A_{i}=\pi \cdot d \cdot h$.

\subsection{Ionization energy}

Our experiment was carried out in nitrogen and on the basis of the literature data there are three ionization energies [7]: $e_{i 1}=1402.3 \mathrm{~kJ} / \mathrm{mol}, e_{i 2}=2856.0 \mathrm{~kJ} / \mathrm{mol}, e_{i 3}=4578.0 \mathrm{~kJ} / \mathrm{mol}$. The energy required to breakdown of the spark is an ionization energy that can form later the arc. Total ionization energy can be calculated for $n$ moles of the gas (nitrogen) in the core of plasma as:

$$
E_{i}=n \cdot e_{i}=e_{i} \cdot \frac{p \cdot V_{i}}{(M R) \cdot T}=e_{i} \cdot \frac{\pi \cdot d^{2} \cdot h}{4 \cdot(M R)} \cdot \frac{p}{T}
$$

The initial temperature $T$ amounts $300 \mathrm{~K}$ and universal gas constant $(M R)=8314 \mathrm{~J} / \mathrm{mol}$. For higher pressure, proportionally the higher ionization energy is required and the same is for lower temperature. However the plasma is formed with smaller radius, the ionization takes place in a higher volume with radius two times bigger.

\subsection{Heat transfer to electrodes}

A certain part of the energy delivered by the secondary circuit is consumed on the heating of the electrodes. In a small time of the sparking the heat transfer takes place on the small area approximately equal the cross section of the electrodes with diameter $d$. The main target is to determine the specific heat conductivity $\alpha$ between the gas and metal. This value $\alpha$ can be obtain from the Nusselt number $\mathrm{Nu}$ [2], gas conductivity $\lambda_{p}$ and a characteristic flow dimension, in this case the diameter of the electrode: 


$$
\alpha=\frac{\mathrm{Nu} \cdot \lambda_{p}}{d}
$$

where $\mathrm{Nu}$ is obtained from Reynolds number Re and Prandtl number Pr. However Ballal and Lefebvre [6] accounted for heat transfer the following expression for Nusselt number:

$$
\mathrm{Nu}=0,61 \cdot \operatorname{Re}_{g}^{0,46}=0,61 \cdot\left(\frac{u_{\infty} \cdot d}{\mu}\right)^{0,46}
$$

where $u_{\infty}$ is gas velocity along the wall and $\mu$ is kinematic viscosity of gas. On the other hand the kinematic viscosity of the gas depends on the temperature $T$ and density $\rho$ according to the formula:

$$
\mu=5,18 \cdot 10^{7} \cdot \frac{T^{0,62}}{\rho} \quad\left[\mathrm{m}^{2} / \mathrm{s}\right]
$$

The conductivity of the gas is calculated based on the basis of Woschni [3] formula:

$$
\lambda_{p}=3,654 \cdot 10^{-4} \cdot T^{0,748} \quad[\mathrm{~W} /(\mathrm{m} \mathrm{K})]
$$

Finally the cooling energy is calculated from the equation:

$$
E_{h}=\left(\frac{1}{2} \pi \cdot d^{2}\right) \cdot \alpha \cdot\left(T-T_{w}\right) \cdot t_{i}
$$

\subsection{Kinetic energy}

Liu et al. [9] assumed that some fraction of the input energy is converted into kinetic energy of the turbulence according to the following formula:

$$
\dot{E}_{k}=4 \cdot \pi \cdot\left(\frac{d}{2}\right)^{2} \cdot \rho_{u} \cdot u^{3}
$$

where $\rho_{u}$ is density, $u$ is the entrainment velocity and $d$ is the kernel diameter. Using this equation the kinetic energy can be calculated for given values: $\rho_{u}=1,403 \mathrm{~kg} / \mathrm{m}^{3}$ and for wave pressure moving with mean velocity $u[\mathrm{~m} / \mathrm{s}]$. During ignition time $t_{l}$ (less than $2 \mathrm{~ms}$ ) the total kinetic energy amounts:

$$
E_{k}=\int_{0}^{t_{i}} \dot{E}_{k} \mathrm{~d} t=\dot{E}_{k} \cdot t_{i}
$$

\section{Ignition efficiency}

Electric efficiency of the ignition systems define also the thermal resistance of these devices, because lower efficiency value decides about higher heating of the coil body and takes effect 
on their durability. On the basis of conducted tests by measurements of the primary (state 1) and secondary (state 2) current and voltage, it is possible to calculate the total electric efficiency of the ignition systems. The total electric efficiency can be defined as follows:

$$
\eta_{e}=\frac{E_{2}}{E_{1}}=\frac{\int_{t_{02}}^{t_{2}} U_{2} I_{2} d t}{\int_{t_{01}}^{t_{1}} U_{1} I_{1} d t}
$$

The electric efficiency for the ignition system with transistor ignition coil from Beru No 0040102002 is shown in Figure 17. The test of energy efficiency was done for 6 probes for every point of measurements. The electric efficiency is very small and at assumed initial pressures does not exceed $30 \%$. The rest of energy goes into the surroundings in a form of heat. Lower efficiency is observed for nitrogen as the neutral gas. The same input energy for all considered cases amounted $210.74 \mathrm{~mJ}$.

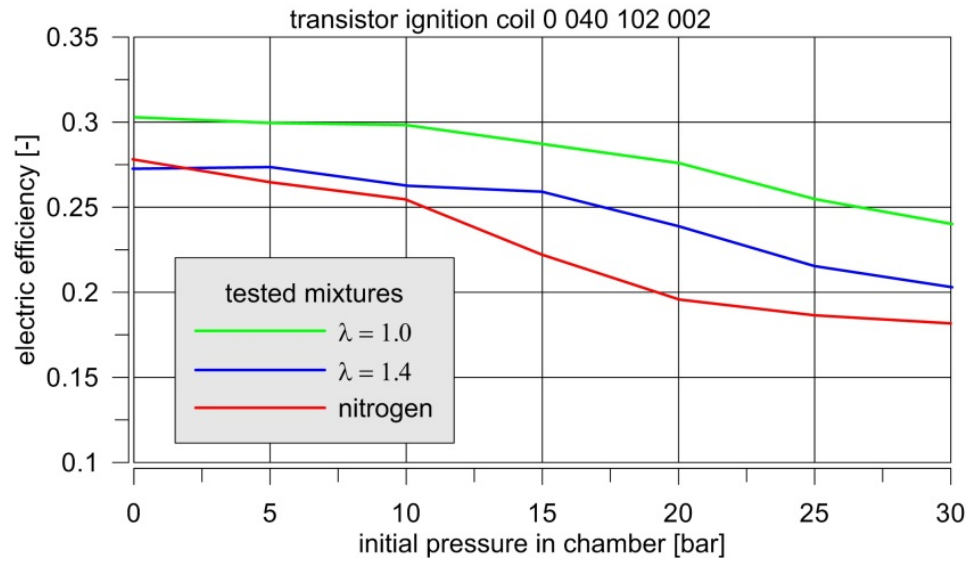

Figure 17. Electric efficiency of ignition system for two mixtures and nitrogen

\section{Energy balance during ignition}

On the basis of the carried out experimental tests and the theoretical considerations the balance of the energies delivered to the chamber from the secondary circuit of the coil can be done by Sankey chart. The carried out calculations determine the following values of heat losses for the case $p=25$ bars and spark plug with the normal electrodes: 1) radiation - $E_{r}=$ $7.8 \mathrm{~mJ}, 2$ ) ionization $-E_{i}=7.2 \mathrm{~mJ}, 3$ ) heat transfer $\left.-E_{h}=31 \mathrm{~mJ}, 4\right)$ kinetic energy $-E_{k}=9 \mathrm{~mJ}$.

Calculated total losses amount $55 \mathrm{~mJ}$ and measurements show that the thermal energy delivered to the charge $E_{\text {th }}$ amounts only $4.23 \mathrm{~mJ}$. On the other hand the measured energy delivered by the secondary circuit amounts $E_{2}=61.05 \mathrm{~mJ}$. The other non-considered heat losses amount $E_{c}=1.82 \mathrm{~mJ}$. The graphical presentation of the participation of particular 
energies for the spark plug with normal electrodes and with 'thin' electrodes is shown on the Sankey diagram (Figure 18).

The energetic balance shows that the heat transfer to the electrodes consumes a half of delivered energy during the sparking process. Decrease of the cross-section of the electrodes to $25 \%$ of their initial value causes the increase of the thermal efficiency almost twice with decrease of the heat transfer to the electrodes. The work done by Liu et al [5] shows the discharge efficiency of different ignition system and for conventional spark ignition system this efficiency is below 0.1 (10\%) despite the bigger coil energy (above $100 \mathrm{~mJ}$ ).

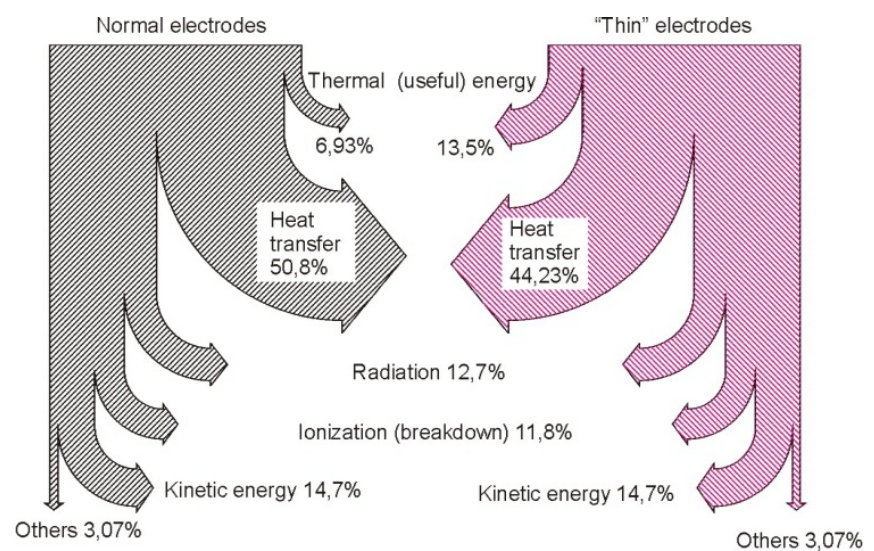

Figure 18. Balance of energy in the conventional ignition system for 2 types of the electrodes

\section{CFD simulation of ignition and combustion process of CNG mixtures}

Propagation of flame (temperature and gas velocity) depends on the temporary gas motion near the spark plug. The ignition process in SI gaseous engines was simulated in CFD programs (KIVA and Phoenics). Setting of the electrodes in direction of gas motion influences on spreading of the flame in the combustion chamber.

\subsection{Propagation of ignition kernel}

The propagation of the temperature during ignition process depends on the gas velocity between the spark electrodes. The experimental tests show an absence of the combustion process in the engine without gas motion. The combustion process can be extended with a big amount of hydrocarbons in the exhaust gases. The propagation of the temperature near the spark electrodes was simulated by use of Phoenics code for horizontal gas velocity amounted $10 \mathrm{~m} / \mathrm{s}$ with taking into account the heat exchange, radiation, ionization and increase of the internal energy. The model of the spark ignition contained 40x40x1 cells with two solid blocks as electrodes and one block of the plasma kernel. The electrodes were heated during $1 \mathrm{~ms}$ with energy equal $8 \mathrm{~mJ}$ as it was determined during experimental tests. Propagation of the temperature near spark electrodes is shown in Figure 20 for two times 0.4 and $0.8 \mathrm{~ms}$, respectively. 

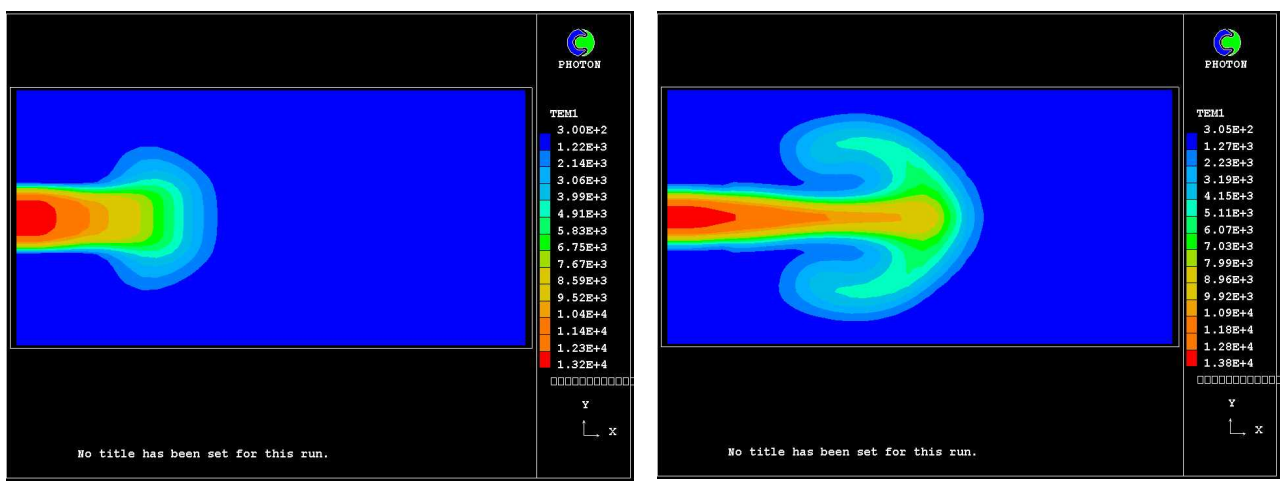

Figure 19. Temperature in the charge during ignition after 0.4 and $0.8 \mathrm{~ms}$

The temperature inside the plasma grows as a function of the power of the secondary circuit in the coil and the velocity of the charge causes propagation of the temperature from the sparking arc outside of the plasma. Temperature inside the plasma kernel reaches value about $13000 \mathrm{~K}$.

\subsection{CNG ignition process in caloric chamber}

The first step of the experimental tests was an observation of the ignition of the mixture of CNG and the air in the caloric chamber and the second step by use the simulation. The cylinder model has diameter $\mathrm{D}=34 \mathrm{~mm}$ and height $\mathrm{B}=22 \mathrm{~mm}$. Volume of the chamber corresponds to the minimal volume of the combustion chamber in the engines of displacement $260 \mathrm{~cm}^{3}$ and compression ratio 14 .

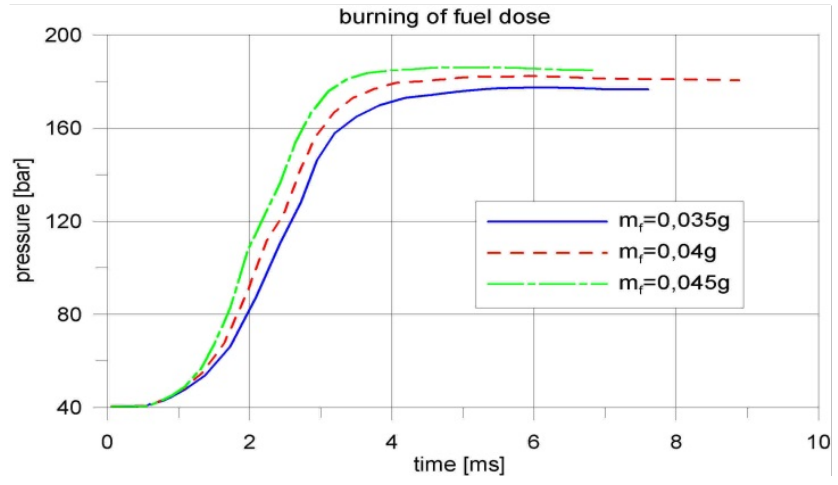

Figure 20. Increment of the pressure during combustion in the caloric chamber

Prediction of the mixture parameters in the chamber during combustion process was carried out by using the open source code of KIVA3V [4]. The complex test was conducted for 3 dose of CNG: $0.035,0.04$ and $0.045 \mathrm{~g}$, which corresponds to air excess coefficients $\lambda: 1.58,1.38$ and 1.23 , respectively at initial pressure 40 bars and temperature $600 \mathrm{~K}$. At assumption of the high compression pressure in the caloric chamber it was obtained very high level of final 
pressure (about 180 bars) after burning of the whole dose (Figure 20). Velocity of increment of the mean charge temperature inside the caloric chamber depends on the value of the fuel dose (Figure 21) and for bigger dose the quicker increment of the temperature is observed.

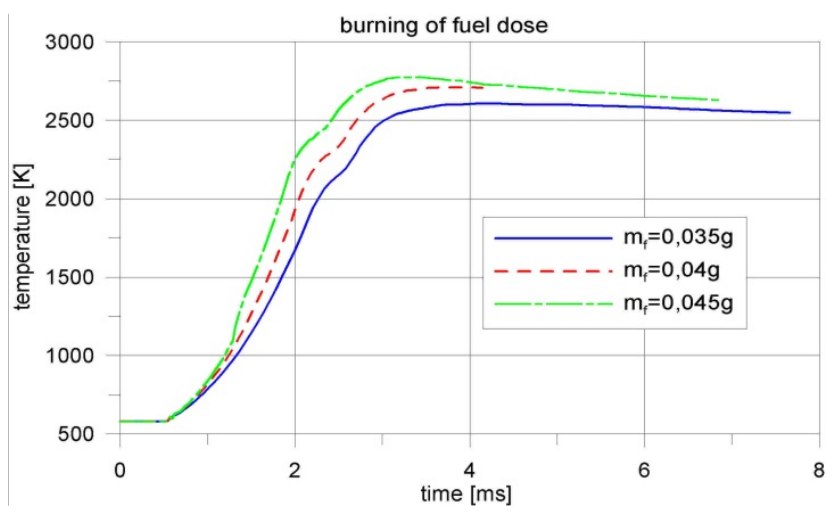

Figure 21. Variation of the temperature in the caloric chamber for different dose of $\mathrm{CNG}$

25

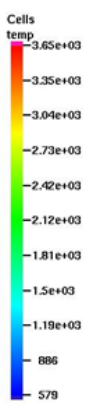

76

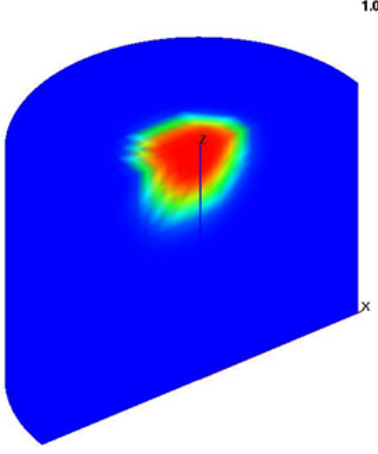

(a)
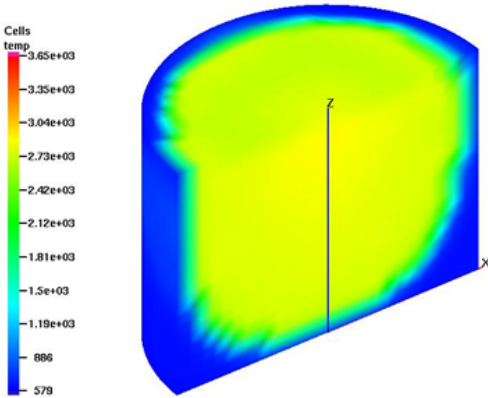

$1.081341 \mathrm{e}+01 \quad 55$

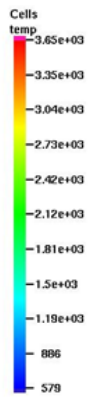

4.419611e+01 169

(c)

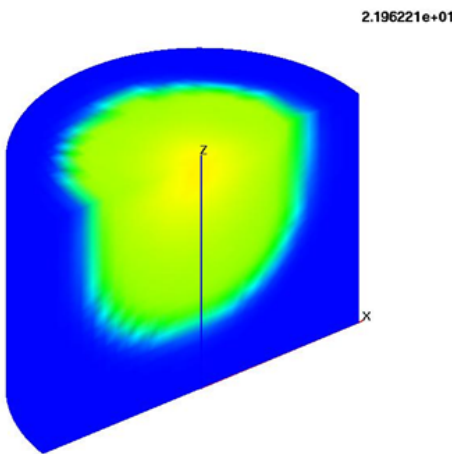

(b)

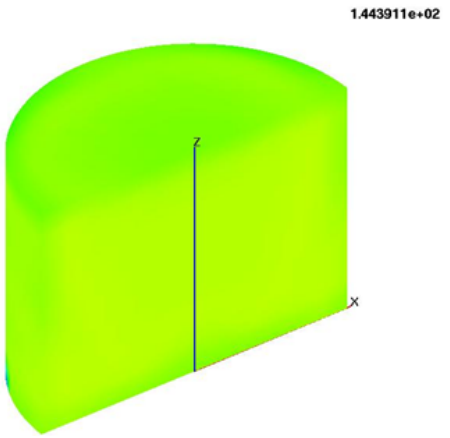

(d)

Figure 22. Temperature in the caloric chamber after initiation of combustion: a) $0.5 \mathrm{~ms}, \mathrm{~b}) 0.6 \mathrm{~ms}$, c) $1.85 \mathrm{~ms}, \mathrm{~d}) 7.4 \mathrm{~ms}$ 
The dose of fuel influences on variation of all thermodynamic parameters. The initiation of the combustion process lasted about $0.5 \mathrm{~ms}$ for all dose of the fuel. The complete combustion of all doses of the fuel without swirl and tumble follows after $4 \mathrm{~ms}$ with assumption of heat transfer to the walls. Four slides in Figure 22 show the spreading of the flame in the caloric chamber from the spark plug to the walls almost spherically. The maximum of temperature near spark plug amounts almost $3600 \mathrm{~K}$ and after combustion process decreases to $2700 \mathrm{~K}$.

\subsection{Verification of ignition modelling}

The initial simulations of the CNG combustion was carried out on the model of the chamber used for the experimental tests on the Schlieren stand in a steady state initial conditions. The chamber had the volume equalled $100 \mathrm{~cm}^{3}$ with diameter $\mathrm{D}=80 \mathrm{~mm}$ and width $\mathrm{B}=20 \mathrm{~mm}$. The initiation of the ignition followed in the centre of the chamber by two thin electrodes. The chamber was filled by natural gas at 5 bars and $\lambda=1.4$. The initial temperature of the charge amounted $300 \mathrm{~K}$, so this required much more electrical energy than for firing engine. The ignition energy was simulated as additional internal energy in the centre of the combustion chamber. The LES model for fully premixed charge was used in the CFD open source program OpenFOAM. The classical idea is to use a filter which allows for the separation of large and small length scales in the flow-field. Applying the filtering operator to the Navier-Stokes equations provides a new equation governing the large scales except for one term involving the small velocity scale. The model of combustion chamber was

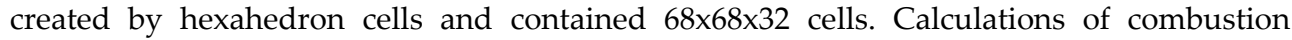
process were carried out in 64-bit Linux system with visualisation of results by use Paraview software. The combustion process in the chamber lasted a long time (above $50 \mathrm{~ms}$ ), because of absence of the gas motion. The oxidation of methane was simulated by the OpenFOAM combustion procedure in Xoodles module. Thermodynamic properties of the charge were calculated by using JANAF tables. Increase of pressure in the flat combustion chamber without initial swirl or "tumble" of the charge is shown in Figure 23.

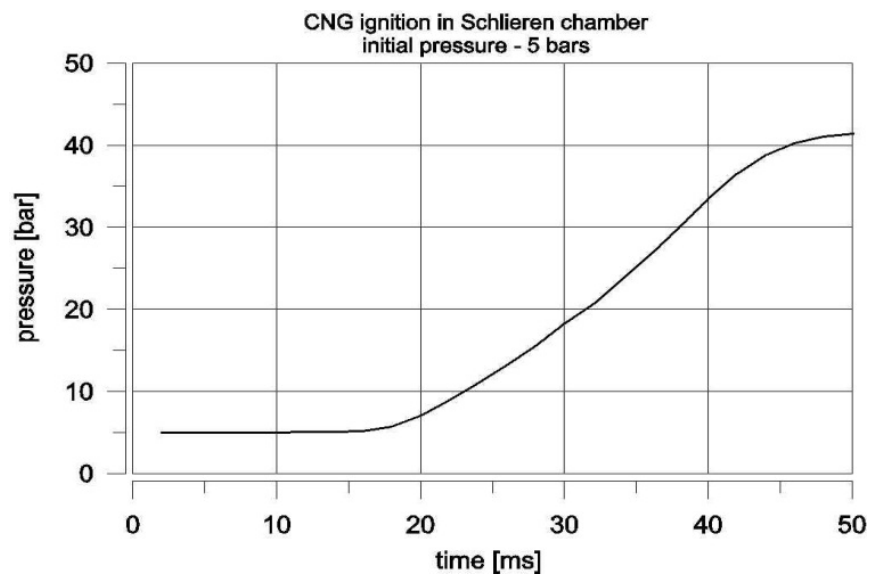

Figure 23. Increase of pressure in the chamber after ignition 
The combustion process involves the change of thermodynamic parameters of the gas, which can be observed by moving of flame with different temperature, pressure and density in burned and unburned spaces. Full combustion of the methane-air mixture lasts longer than in the real engine combustion chamber at the same geometry of the combustion chamber. The propagation of chemical reactions is radial and the thick boundary of the combustion (about $8 \mathrm{~mm}$ ) is observed because of the lean mixture. Propagation of the flame causes the radial compression of the gas between unburned and burned regions and thin area of twice higher density is formed. Figure 9 shows distribution of gas density in the chamber after $18 \mathrm{~ms}$ from start of ignition. Red colour indicates density on the level 0.0118 $\mathrm{g} / \mathrm{cm}^{3}$ and blue colour only $0.005 \mathrm{~g} / \mathrm{cm}^{3}$.
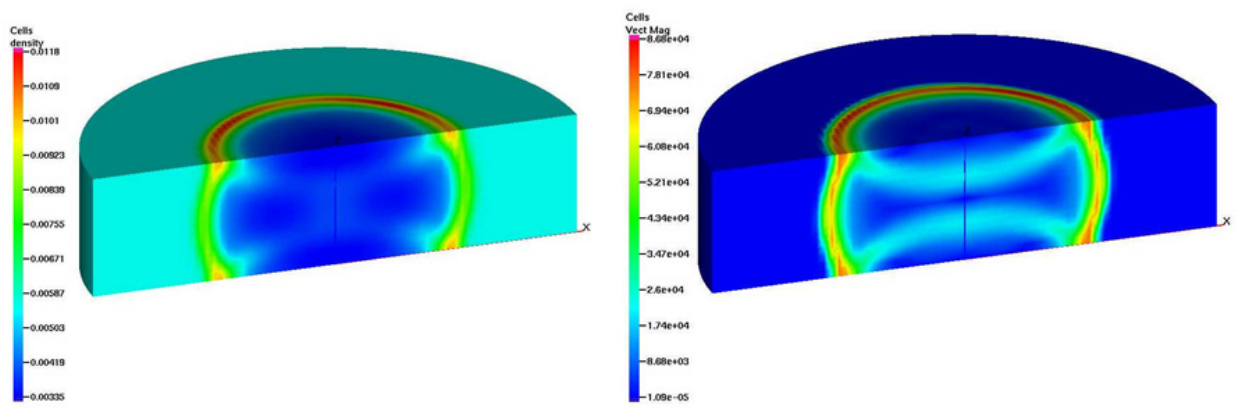

Figure 24. Gas density and absolute gas velocity after $18 \mathrm{~ms}$ from beginning of ignition

Combustion process in the narrow area takes place with turbulent velocity. Turbulence causes penetration of the flame into the unburned mixture with velocity higher than laminar combustion speed. For the methane-air stoichiometric mixture the combustion laminar speed amounts only $40 \mathrm{~cm} / \mathrm{s}$. For the considered case the absolute velocity of combustion in the flame region amounts about $80 \mathrm{~m} / \mathrm{s}$ as one is shown in Fig.10. However, total combustion speed is very low and is close to the laminar speed of methane-air mixture $0.4 \mathrm{~m} / \mathrm{s}$.

Experimental tests on the Schlieren stand done by Sendyka and Noga [11] showed also radial propagation of the flame defined by the change of the charge density. Figure 25 shows the films of the flame propagation in the chamber at 3, 7, 40 and $54 \mathrm{~ms}$ after start of the ignition, respectively. The ignition of the CNG and air mixture with initial pressure 5 bars and initial temperature $300 \mathrm{~K}$ was initiated by two thin electrodes in centre of the combustion chamber. The charge was fully premixed with air excess ratio $\lambda=1.4$. The flame is distorted by touching into the quartz glass in the chamber, which is observed by hell circle inside the black circle. The change of gas density influences on the distortion of the laser beam and photos show development of the flame during combustion process. The experimental test proves the result obtained from simulation by using LES combustion model in the OpenFOAM program. 

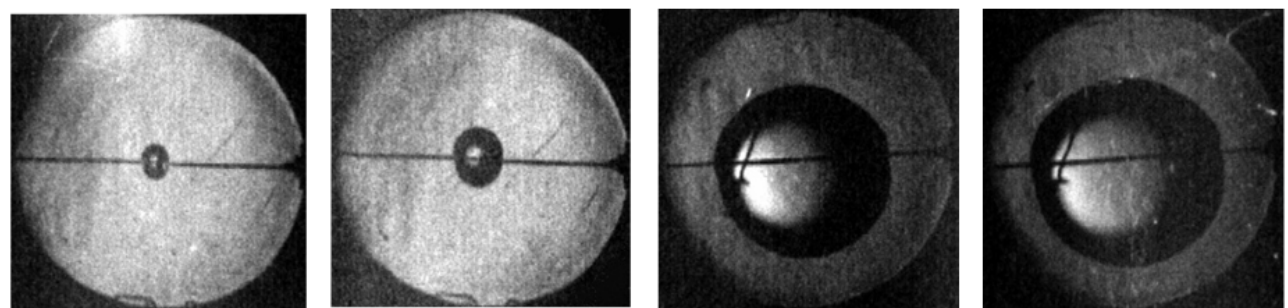

Figure 25. Schlieren stand - combustion boundary of the flame after 3, 7, 40 and $54 \mathrm{~ms}$ [15]

Both simulation and experiment do not show deviation of the spherical combustion flame. The experiment demonstrated velocity of combustion in radial direction of value $40 \mathrm{~cm} / \mathrm{s}$.

\subsection{Mixture motion and ignition}

The most important factor influencing on the ignition is the charge motion through the spark plug. Two kinds of motions were considered: swirl and tumble caused by valve and inlet profile, combustion chamber and squish. The combustion process is strongly connected with turbulence of the charge and only small part is the laminar speed of the total combustion velocity. Simulation was carried out in the rectangular space with central location of the spark plug. The mesh of the combustion chamber model with length and width $5 \mathrm{~cm}$ and height $3 \mathrm{~cm}$ was divided into 288000 cells with rectangular prism $(\mathrm{NX}=80$, $\mathrm{NY}=80$ and $\mathrm{NZ}=45$ ). The calculations were carried out in transient conditions (initial time step $1 \mathrm{e}-6 \mathrm{~s}$ in time $t=5 \mathrm{~ms}$ ). The spark plug was located in the centre of the calculation space and the object of the electrodes was created by CAD system. The mesh in the region of the spark plug electrodes contains fine grids with cell length equal $0.3 \mathrm{~mm}$ in $\mathrm{x}$ and $\mathrm{y}$ axis.

At the first the ignition of CNG was simulated with "initial tumble" $\omega_{y}=250 \mathrm{rad} / \mathrm{s}$ and $\mathrm{p}=20$ bars. The charge with velocity about $15 \mathrm{~m} / \mathrm{s}$ flew through the gap of the spark plug causing the propagation of the flame inside the chamber. The simulation of combustion and gas movement was carried out also by Phoenics, which takes into account turbulence model and simple combustion of compressible fluid. The charge motion is connected with high turbulence and this causes also the higher combustion rate.

Distribution of the combustion products in the modelled space is shown in Figure 26 at 0.5 $\mathrm{ms}$ and $1.2 \mathrm{~ms}$ after start of the ignition, respectively. After short time (about $1 \mathrm{~ms}$ ) the whole charge is burned in the calculation space. The higher flow velocity is between the electrodes of the spark plug. The other simulation was carried out for the central swirl around the spark plug with swirl velocity $15 \mathrm{~m} / \mathrm{s}$ on the mean radius $1.5 \mathrm{~cm}$. In this case the interaction of the electrode shape is seen - the propagation of the flame is faster in the opened site of the electrodes. Figure 27 presents development of combustion process after 1 and $4 \mathrm{~ms}$ from beginning of the ignition.

The swirl in the chamber influences on the irregular propagation on the flame and extends the combustion process. Even after $4 \mathrm{~ms}$ the combustion of the methane is not full. Velocity 
of the gas flow in the spark plug gap is smaller than in the "tumble" case. For this reason the propagation of the combustion products and flame is not uniform.
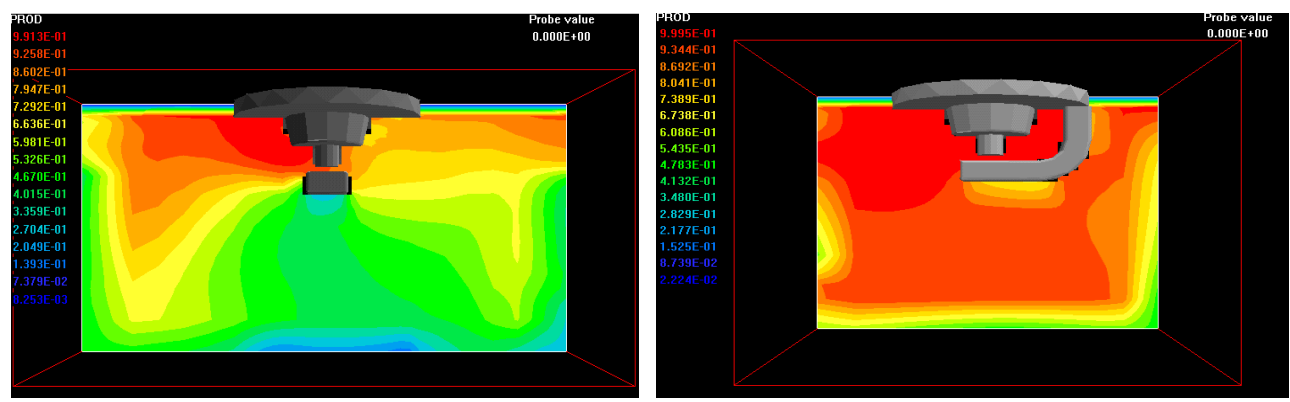

Figure 26. Combustion products with initial "tumble" charge motion after $0.5 \mathrm{~ms}$ and after $1.2 \mathrm{~ms}$
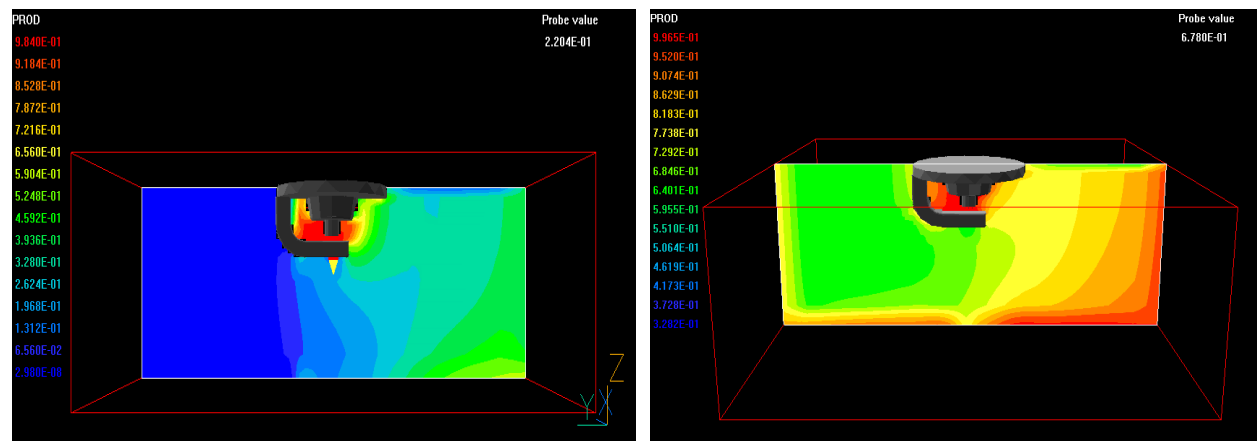

Figure 27. Combustion products with initial "swirl" charge motion after $1 \mathrm{~ms}$ and after $4 \mathrm{~ms}$

\section{Conclusions}

The chapter contains results of theoretical, modelling and experimental work considered to factors, which have very big impact on the ignition of gaseous fuels in combustion engines. On the fact of more and more important role of gaseous engines, particularly those fuelled by natural gas, definition of good conditions for ignition of gaseous fuels is one of the task of development of modern spark ignition gaseous engines, particularly with high charging ratio. Experimental works with CNG ignition were done in the caloric chamber, however in conditions closed to real conditions of engine work. On the presented considerations one can draw some conclusions and remarks:

1. Gaseous fuels, such as CNG requires higher electric energy delivered by the ignition system. Higher pressure in the combustion chamber increases internal energy near the spark plug and requires also higher secondary voltage of the ignition coil. For gaseous leaner mixtures an ignition system with higher energy is needed (above $60 \mathrm{~mJ}$ ). 
2. The higher initial pressure increases the thermal efficiency of the ignition system.

3. For the conventional ignition systems even with high secondary energy above $60 \mathrm{~mJ}$ only a small part maximum $15 \%$ of it is consumed by the charge.

4. The maximum of thermal efficiency was obtained at initial pressure 25 bars with value of $13,5 \%$ for the spark plug with thin electrodes and only $1 \%$ at ambient pressure and temperature.

5. The spark plug with thin electrodes indicates higher thermal efficiency than the spark plug with normal electrodes. This is caused by small heat exchange with the electrode' walls.

6. The energy losses consist of heat exchange, ionization energy (breakdown), radiation and others. The biggest of them are the heat transfer to the spark electrodes and radiation.

7. On the basis of CFD simulation one proved that nature of mixture motion (tumble or swirl) in the combustion chamber influences on propagation velocity of the ignition kernel and combustion process.

8. Ignition in CNG diesel engine can be caused by injection of small ignition dose of diesel oil.

\section{Author details}

Wladyslaw Mitianiec

Cracow University of Technology, Cracow, Poland

\section{Acknowledgement}

The author would like to acknowledge the financial support of the European Commission in integrated project "NICE" (contract TIP3-CT-2004-506201). Personally I would like to acknowledge the contribution of the Cracow University of Technology, particularly Prof. B. Sendyka for supervising during the project and Dr. M. Noga for his big input in the experimental work.

\section{References}

[1] Heywood J (1988), Internal Combustion Engine Fundamentals, Mc Graw-Hill, New York

[2] Look D.C., Sauer H.J (1986), Engineering Thermodynamics, PWS Engineering, Boston

[3] Mitianiec W., Jaroszewski A. (1993), Mathematical models of physical processes in small power combustion engines (in polish), Ossolineum, Wroclaw-Warszawa-Krakow

[4] Ramos J.I (1989), Internal combustion modeling, Hemisphere Publishing Corporation, New York

[5] Amsden A.A. et al (1989), KIVA-II - A Computer Program for Chemically Reactive Flows with Sprays, Los Alamos National Lab., LA-11560-MS 
[6] Ballal D., Lefebvre A (1981), The Influence of Flow Parameters on Minimum Ignition Energy and Quenching Distance, 15th Symposium on Combustion, pp.1737-1746, The Combustion Institute, Pittsburgh

[7] Eriksson L (1999), Spark Advance Modeling and Control, Linkoping University, dissertation No 580, Linkoping

[8] Hires S.D., Tabaczyński R.J (1978), The Prediction of Ignition Delay and Combustion Intervals for Homogeneous Charge, Spark Ignition Engine, SAE Pap. 780232

[9] Liu J.,Wang F., Lee L., Theiss N., Ronney P (2004), Gundersen M., Effect of Discharge Energy and cavity Geometry on Flame Ignition by Transient Plasma, 42nd Aerospace Sciences Meeting, 6th Weakly Ionized Gases Workshop, Reno, Nevada

[10] Maly R., Vogel M (1979), Initiation and propagation of Flame Fronts in Lean CH4 - Air Mixtures by a Three Modes of the Ignition Spark, Seventeenth Symphosium on Combustion, pp 821-831, The Combustion Institute, Pittsburgh

[11] Sendyka B., Noga M (2007), Propagation of flame whirl at combustion of lean natural gas charge in a chamber of cylindrical shape, Combustion Engines, 2007-SC2, Bielsko Biała

[12] Spadaccini L.J.,Tevelde J.A (1980), Autoignition Characteristic of Aircraft Fuels, NASA Contractor Report Cr-159886

[13] Thiele M., Selle S., Riedel U., Warnatz J.,Maas U (2000), Numerical simulation of spark ignition including ionization, Proceedings of the Combustion Institute, Volume 28, pp. 1177- 1185

[14] Vandebroek L.,Winter H., Berghmans J (2000), Numerical Study of the Auto-ignition Process in Gas Mixtures using Chemical Kinetics, K.U.Leuven, Dept. Of Mechanical Engineering, 2000

[15] FEV (2004) information materials, Aachen 